\title{
The meaning of my feelings depends on who I am: Work-related identifications shape emotion effects in organizations
}

\author{
Conroy, Samantha A ; Becker, William J ; Menges, Jochen I
}

\begin{abstract}
Theory and research on affect in organizations has mostly approached emotions from a valence perspective, suggesting that positive emotions lead to positive outcomes and negative emotions to negative outcomes for organizations. We propose that cognition resulting from emotional experiences at work cannot be assumed based on emotion valence alone. Instead, building on appraisal theory and social identity theory, we propose that individual responses to discrete emotions in organizations are shaped by, and thus depend on, work-related identifications. We elaborate on this proposition specifically with respect to turnover intentions, theorizing how three discrete emotions-anger, guilt, and pride-differentially affect turnover intentions, depending on two work-related identifications: organizational and occupational. A longitudinal study involving 135 pilot instructors reporting emotions, work-related identifications, and turnover intentions over the course of one year provides general support for our proposition. Our theory and findings advance emotion and identity theories by explaining how the effects of emotions are dependent on the psychological context in which they are experienced.
\end{abstract}

DOI: https://doi.org/10.5465/amj.2014.1040

Posted at the Zurich Open Repository and Archive, University of Zurich

ZORA URL: https://doi.org/10.5167/uzh-172290

Journal Article

Published Version

Originally published at:

Conroy, Samantha A; Becker, William J; Menges, Jochen I (2017). The meaning of my feelings depends on who I am: Work-related identifications shape emotion effects in organizations. Academy of Management Journal, 60(3):1071-1093.

DOI: https://doi.org/10.5465/amj.2014.1040 


\section{Marnal}

\section{The Meaning of My Feelings Depends on Who I Am: Work- related Identifications Shape Emotion Effects in Organizations}

\begin{tabular}{|c|c|}
\hline Journal: & Academy of Management Journal \\
\hline Manuscript ID & AMJ-2014-1040.R3 \\
\hline Manuscript Type: & Revision \\
\hline Keywords: & $\begin{array}{l}\text { Mood and emotions < Attitudes, Cognitions, and Affect }<\text { Organizational } \\
\text { Behavior }<\text { Topic Areas, Attitudes, cognitions, and affect (General) }< \\
\text { Attitudes, Cognitions, and Affect < Organizational Behavior }<\text { Topic Areas, } \\
\text { Social identity theory }<\text { Theoretical Perspectives }\end{array}$ \\
\hline Abstract: & $\begin{array}{l}\text { Theory and research on affect in organizations has mostly approached } \\
\text { emotions from a valence perspective, suggesting that positive emotions } \\
\text { lead to positive outcomes and negative emotions to negative outcomes for } \\
\text { organizations. We propose that cognition resulting from emotional } \\
\text { experiences at work cannot be assumed based on emotion valence alone. } \\
\text { Instead, building on appraisal theory and social identity theory, we propose } \\
\text { that individual responses to discrete emotions in organizations are shaped } \\
\text { by, and thus depend on, work-related identifications. We elaborate on this } \\
\text { proposition specifically with respect to turnover intentions, theorizing how } \\
\text { three discrete emotions - anger, guilt, and pride - differentially affect } \\
\text { turnover intentions, depending on two work-related identifications - } \\
\text { organizational and occupational identification. A longitudinal study } \\
\text { involving } 135 \text { pilot instructors reporting emotions, work-related } \\
\text { identifications, and turnover intentions over the course of one year } \\
\text { provides general support for our proposition. Our theory and findings } \\
\text { advance emotion and identity theories by explaining how the effects of } \\
\text { emotions are dependent on the psychological context in which they are } \\
\text { experienced. }\end{array}$ \\
\hline
\end{tabular}




\title{
The Meaning of My Feelings Depends on Who I Am: Work-Related Identifications Shape Emotion Effects in Organizations
}

\author{
Samantha A. Conroy \\ Colorado State University \\ Samantha.conroy@colostate.edu \\ William J. Becker \\ Virginia Tech \\ beckerwj@yahoo.com \\ Jochen I. Menges \\ WHU - Otto Beisheim School of Management \\ jochen.menges@whu.edu
}

\begin{abstract}
Acknowledgements: We would like to gratefully acknowledge our action editor, Brent Scott, and three anonymous reviewers whose feedback improved our work immensely. We would also like to thank Laura Little, Dan Ganster, and Lynn Shore for providing feedback on prior drafts of this paper. This research was also supported by the TCU Neeley School of Business Research Committee.
\end{abstract}




\section{THE MEANING OF MY FEELINGS DEPENDS ON WHO I AM: WORK-RELATED IDENTIFICATIONS SHAPE EMOTION EFFECTS IN ORGANIZATIONS}

Theory and research on affect in organizations has mostly approached emotions from a valence perspective, suggesting that positive emotions lead to positive outcomes and negative emotions to negative outcomes for organizations. We propose that cognition resulting from emotional experiences at work cannot be assumed based on emotion valence alone. Instead, building on appraisal theory and social identity theory, we propose that individual responses to discrete emotions in organizations are shaped by, and thus depend on, work-related identifications. We elaborate on this proposition specifically with respect to turnover intentions, theorizing how three discrete emotions - anger, guilt, and pride - differentially affect turnover intentions, depending on two work-related identifications - organizational and occupational identification. A longitudinal study involving 135 pilot instructors reporting emotions, work-related identifications, and turnover intentions over the course of one year provides general support for our proposition. Our theory and findings advance emotion and identity theories by explaining how the effects of emotions are dependent on the psychological context in which they are experienced. 
The ongoing "affective revolution" has produced greater appreciation for the importance of emotions in understanding organizational behavior (Barsade, Brief, \& Spataro, 2003: 3) Research in this area has focused primarily on positive and negative affect (i.e. pleasant and unpleasant emotions or moods), and has been guided by the "symmetrical assumption" that employees' positive feelings are beneficial and negative feelings are detrimental for organizations (Lindebaum \& Jordan, 2012: 1027). More recently, there is growing recognition that organizational life is rife with more specific discrete emotions (e.g., pride, anger, guilt), and that each discrete emotion has unique implications for employee behavior (Butt \& Choi, 2006; Butts, Becker, \& Boswell, 2015; Lench, Flores, \& Bench, 2011; Scott \& Judge, 2006; Weiss, Suckow, \& Cropanzano, 1999).

Despite these advances, understanding about how emotions affect outcomes in organizations is still underdeveloped. There is little knowledge concerning cases when the same discrete emotion has different effects, depending on the circumstances. Yet, recent work points to this possibility. For example, research on the discrete emotion of envy theorizes that envy can motivate individuals to improve their own efforts, to help others, or to sabotage the efforts of others (Tai, Narayanan, \& McAllister, 2012; Van de Ven, Zeelenberg, \& Pieters, 2009). A further complexity is the possibility that different discrete emotions, even those with opposite valence (i.e., positive and negative), may have similar effects under some conditions. For example, negative feelings have been found to increase absenteeism while positive feelings have been found to decrease absenteeism (Pelled \& Xin, 1999). Yet, it has also been argued that positive feelings may, in some cases (i.e., when experienced in non-work contexts), lead people to be absent from work as a mood control mechanism (George, 1989: 322). Taken together, there 
are indications that responses to discrete emotions are not as simple as previously thought; theory based on the symmetrical assumption cannot accommodate such complexities.

To advance understanding of how emotions unfold at work and influence organizationally relevant outcomes, we examine the psychological context within which emotions develop and transform into cognitive responses. We draw on and integrate two major theories: emotion appraisal theory (Lazarus, 1991a), which provides a general process account of how discrete emotions and response tendencies emerge from individuals' interpretations of events; and social identity theory (Ashforth \& Mael, 1989; Tajfel \& Turner, 1985), which explains how individuals' self-definitions (i.e., identities) relate to group membership and influence individual needs, beliefs, and behaviors. We propose that the appraisal process elicited by work events is shaped by the psychological context that employees' social identities provide. Self-definitions are a critical contextual factor for emotions given their role in individual motives and sense-making processes (Lazarus, 1991a). Indeed, in his influential work on emotions, Lazarus noted that identity or self "is involved in every emotion" (1991a: 100). Moreover, research suggests that social identifications have "orienting effects," influencing how events are interpreted and guiding action (Hekman, Steensma, Bigley, \& Hereford, 2009: 1327). We apply these ideas to appraisal theory to explain how employees' work-related identifications influence the relationship between three discrete emotions - anger, guilt, and pride - and turnover intentions.

Two group memberships carry particular importance for employees' social identities: the membership with the organization for which they work, and the membership with the occupational group to which they belong (Gouldner, 1957). We suggest that the extent to which employees identify with their organization or their occupation (or with both or neither) will 
affect how affective events are appraised and, in turn, how the resulting emotion will affect employees' turnover intentions. We test our theory in a flight training and instruction firm with an experience sampling study. Specifically, we assess how within-person variations in anger, guilt, and pride triggered by job and organizational events relate to turnover intentions over a period of one year, depending on employees' work-related identification levels.

Our research offers three main contributions to the management literature. First, we develop boundary conditions around the effects of discrete emotions on outcomes important to organizations. Based on the importance of identifications in meaning-making processes (Weick, Sutcliffe, \& Obstfeld, 2005), we integrate social identity theory with emotion appraisal theory to identify these boundaries and clarify the process of emotion appraisals at work. Prior work has addressed the importance of studying discrete emotions to move beyond the valence-only (i.e., positive and negative) treatment of emotion (e.g., Butts et al., 2015; Lench et al., 2011; Scott \& Judge, 2006). We take this further by theorizing the conditions under which the same discrete emotion can produce different responses and can push the employee to either engage with or disengage from the workplace. For example, we predict and empirically show that anger can in some cases - when organizational identification is high — decrease turnover intentions, and in other cases — when organizational identification is low-increase turnover intentions. An uncontextualized approach to discrete emotions (i.e., one that specifies a concrete action tendency for a discrete emotion; Frijda, Kuipers, \& ter Schure, 1989) would not be able to account for this pattern of effects.

Second, we move beyond the assumptions of emotion-outcome symmetry. We provide evidence that positive and negative discrete emotions can lead to similar outcomes. For example, we theorize and find that anger and pride are positively related to turnover intentions when 
organizational identification is low and negatively related to turnover intentions when organizational identification is high. A symmetrical assumption about emotions could not explain such a finding (Lindebaum \& Jordan, 2012).

Third, by integrating appraisal theory with social identity theory, we are able to explain why emotions, at times, have asymmetric effects in organizations and demonstrate the power of social identifications in transforming responses to emotions. Specifically, we suggest that emotion appraisals are influenced by the need to protect identity-based motives, and relatedly, the meaning of emotion can be transformed by identifications. Our findings suggest that both organizational and occupational identifications psychologically contextualize responses to work emotions. For example, although guilt is traditionally thought to engage individuals with the target of their guilt (Kitayama, Mesquita, \& Karasawa, 2006), we find that guilt reduces turnover intentions only under certain conditions.

In sum, this research answers calls from emotion researchers to dive deeper into our understanding of discrete emotions, remove assumptions of emotion-outcome symmetry, and better contextualize the experience of emotion at work (Gooty, Gavin, \& Ashkanasy, 2009; Lindebaum \& Jordan, 2012). Although, experientially, positive emotions are pleasant and negative emotions unpleasant, our theory and findings suggest that their respective effects for organizations may not follow the same pattern.

\title{
THEORETICAL BACKGROUND AND HYPOTHESES DEVELOPMENT
}

\author{
Appraisal Theory \\ Appraisal theory concerns the process and content of emotions, and suggests that \\ emotions result from appraisals of the person-environment relationship (Ellsworth \& Scherer, \\ 2003; Frijda, 1986; Lazarus, 1991a; Roseman \& Smith, 2001). Appraisals are elicited by
}


affective events - significant incidents that signal or precipitate change relevant to the person's well-being (Weiss \& Cropanzano, 1996). Multiple appraisal frameworks have been proposed, but appraisal criteria tend to be similar across frameworks (Moors, Ellsworth, Scherer, \& Frijda, 2013). Our theory is based on Lazarus’s (1991a) appraisal framework as it includes generally accepted appraisal criteria, often references identity, self, and ego, and provides a thorough account of emotion responses.

Lazarus’s (1991a) appraisal framework splits the appraisal process into primary and secondary appraisals. Primary appraisal relates to the intensity and nature of the emotion through appraisals of goal relevance, goal congruence, and goal content. Goals, also called motives, needs, or concerns, are defined as anything important to an individual (Moors et al., 2013). Goals can be narrow (e.g., feedback provided on a project) and broad (e.g., what feedback means about one's potential) (Lazarus, 1991a). Emotions are experienced if an event is viewed as goal relevant (i.e., a goal is at stake), and the intensity of the emotion is related to the distance between one's experience and one's goals. Goal congruence pertains to whether the encounter brings one closer to one's goals or further away from them. Experiences appraised as bringing one closer to one's goals invoke positive emotions, while experiences that threaten or pull one further from one's goals invoke negative emotions. Goal content (or ego-involvement) is the appraisal of the event's specific relevance to the individual's goals, though the type of emotion to be experienced as well as the consequent appropriate response is yet to be determined (but is determined as part of the secondary appraisal). For example, if an event is appraised to have goal content involving the self- or social esteem part of the identity, the emotion possibilities narrow to a set of emotions (i.e., anger, anxiety, and pride) rather than to a specific emotion.

The primary appraisal process is important because it assesses whether an event is 
relevant to the person-environment relationship and whether a response is necessary. However, the primary appraisal points mainly to the valence and intensity of the emotion. As such, predictions made regarding basic positive and negative emotions address responses to primary appraisals. Primary appraisals are immediate and automatic, and appraisal theory posits that emotional experiences quickly evoke secondary appraisals as individuals seek to interpret and respond to the emotion-evoking event (Lazarus, 1991a).

Secondary appraisals determine the discrete emotion and the appropriate forms of coping with the emotion through three considerations (Lazarus, 1991a). One is blame or credit - to what extent should blame (in the case of negative emotions) or should credit (in the case of positive emotions) be directed at the self, at another, or be non-directed. The other two secondary appraisals are coping potential — beliefs that one can influence the environment for change_-and future expectations - beliefs that things will be favorable or unfavorable going forward.

An important distinction to be made about appraisal is that it is different from knowledge (Lazarus, 1991a). Knowledge is understanding of the way the world works in general and in specific encounters whereas appraisal is the personal significance of what is known or believed about such encounters. Specific encounters provide knowledge, which is appraised based on "generalized patterns (cognitive and motivational traits) that transcend a specific encounter but that may be regarded by a person as relevant to it" (Lazarus, 1991a: 140). We propose that one's identifications with social groups influence the specific nature of secondary appraisals because identifications produce a set of innate motive patterns relevant to personal significance. For example, identifications can have an influence on beliefs about who or what we define as part of our self, whether coping within the work environment can produce change, and whether similar experiences will continue to occur in the future within the work environment. 


\section{Responses to Emotion at Work}

Because emotion provides important information about goal pursuit, there is an immutable impetus to respond to emotion. Some scholars have focused on action tendency responses (i.e., the immediate urge to act upon emotion, Frijda, 1986). Others have treated responses as "coping," described by Lazarus as "the psychological analogue of action tendencies...more psychological, complex, deliberate, and planful" (1991b: 830). Lazarus (1991b) proposed coping as a critical outcome of emotion, in particular for negative emotions. Positive emotions have action tendencies (Lazarus, 1991a) and influence cognition as well (Fredrickson, 1998), primarily in the form of a desire to continue or enhance the positive emotion experience, though these effects may not be as strong or differentiated as for negative emotions. As such, emotions always produce some response, cognitive or behavioral or both.

Emotion responses can be engaging or disengaging, meaning that the emotion affirms either "interdependence of the self" or "independence of the self" (Kitayama et al., 2006: 891). In the context of organizations, turnover intentions reflect the extent to which employees seek to engage with or disengage from their organization. Thus, turnover intentions are a relevant response to emotions experienced at work. When emotions affirm interdependence within the organization environment, turnover intentions are expected to decrease, but when emotions affirm independence, turnover intentions are expected to increase.

The extent to which a discrete emotion engages or disengages an individual with workrelated groups, and thus leads to a decrease or increase in turnover intentions, is likely to be influenced by an individual's motives and ego structure. Identification is an ideal contextual variable given its central role in thoughts and behaviors through identity motives (Ashforth, 2001; Ashforth, Harrison, \& Corley, 2008). Identity motives represent the needs, goals or 
concerns associated with self-definition. Two of the most studied and accepted identity motives are self-consistency and self-enhancement (Ashforth et al., 2008; Cooper \& Thatcher, 2010; Shamir, 1991). Self-consistency refers to the need to view oneself as consistent across time and across facets of the self (Cooper \& Thatcher, 2010; Shamir, 1991). Self-consistency motives involve the need to think, feel, and behave in ways consistent with one's self-definition (Shamir, 1991). Self-enhancement motives are driven by the need to feel positively about oneself (Ashforth, 2001; Ashforth et al., 2008; Hogg, Terry, \& White, 1995; Tajfel \& Turner, 1985). Fulfilling self-enhancement needs through social identification requires that the social group with which one identifies be held in high regard (Ashforth \& Kreiner, 1999; Ellemers, Van Rijswijk, Roefs, \& Simons, 1997; Elsbach \& Kramer, 1996). Because these identity motives provide the psychological context within which emotions are experienced, we suggest that they hold important implications for how secondary appraisals and coping responses unfold.

\section{Discrete Emotions}

One challenge of studying discrete emotions is selecting a limited set of emotions to consider. The selection process, in light of multiple discrete emotion frameworks and over 100 descriptive feeling words indicating discrete emotions (Izard, 2009; Shaver, Schwartz, Kirson, \& O’Connor, 1987), must be guided by clear criteria. Therefore, we established four such criteria. First, we chose emotions that are commonly experienced in work environments, specifically achievement emotions (i.e., "emotions tied directly to achievement activities or achievement outcomes” Pekrun, 2006: 317; Perry, Stupnisky, Hall, Chipperfield, \& Weiner, 2010) that are likely to occur in organizations where individuals are pursuing goals at multiple levels (e.g., goals for oneself, goals for the organization). Second, we chose emotions likely to facilitate engagement and disengagement responses relevant to turnover intentions. Third, we chose 
emotions that were different experientially such that individuals would be able to readily discern between them. Fourth, we chose to investigate both negative and positive discrete emotions.

Based on these criteria, we chose to examine anger, guilt, and pride. Each of these emotions are frequently experienced in organizational contexts (Basch \& Fisher, 1998; Lazarus \& Cohen-Charash, 2001) and have been identified as achievement-oriented (Pekrun, 2006; Perry et al., 2010). Anger, guilt, and pride also have responses pertinent to organizational exit (Carver \& Harmon-Jones, 2009; Kitayama et al., 2006; Schmader \& Lickel, 2006; Shaver et al., 1987). These three emotions are unique in their appraisals (Lazarus \& Cohen-Charash, 2001) and readily distinguishable from each other (Shaver et al., 1987). These emotions have also been the focus of prior organizational research on discrete emotions (Butt \& Choi, 2006; Weiss, Suckow, \& Cropanzano, 1999). Anger and guilt are considered negative emotions, whereas pride is seen as a positive emotion. It is notable that positive emotions are less differentiated in comparison to negative emotions (Dasborough, 2006; Fredrickson, 1998; Ellsworth \& Smith, 1988), and few positive emotions have the same specificity in appraisals and responses (Fredrickson, 1988). As such, we chose one positive emotion - pride, an emotion with clear appraisal characteristics, achievement-orientation, and a high level of ego-relevance (Lewis, 2008; Roseman, Antoniou, \& Jose, 1996). Thus, we develop hypotheses regarding the relationship between anger, guilt, and pride and turnover intentions depending on work-related identifications.

\section{Organizational Identification}

As noted, identifications are important to meaning making processes likely to be engaged when emotions are experienced. Research indicates that organizational identification, i.e., the overlap of an individual's self-definition with an organization's central characteristics (Ashforth \& Mael, 1989; Dutton, Dukerich, \& Harquail, 1994), is particularly relevant to one's 
interpretations of and responses to affective events at work (Hekman, Bigley, Steensma, \& Hereford, 2009; Hekman, Steensma et al., 2009). Furthermore, organizational identification is one of the most commonly studied work-related identifications and has an empirical relationship with turnover intentions (Abrams, Ando, \& Hinkle, 1998). Given the centrality of organizational identification to both turnover intentions and event interpretation, we develop our hypotheses by starting with examining how organizational identification affects the relationship between each of the three emotions and turnover intentions.

The primary appraisal for anger is that an event is goal relevant and goal incongruent, meaning anger is experienced as a negative emotion. In previous studies, higher intensity negative emotions have been associated with increased turnover intentions (Cropanzano, James, \& Konovsky, 1993; Maertz \& Griffeth, 2004) because leaving the organization allows the employee to avoid the discomfort of the negative emotion (Maertz \& Griffeth, 2004).

When organizational identification is high, self-consistency motives should buffer the undesirable effects of negative emotions. Staying with the organization fulfills the selfconsistency motive; therefore, to the extent that individuals identify with the organization, they should be less likely to respond to negative feelings by disengaging. One cannot easily go elsewhere and find an organization with the same organizational identity. Leaving the organization for those highly identified is likely to lead to a strong sense of loss (Conroy \& O'Leary-Kelly, 2014) as the individual's work-related identity features a specific, nontransferrable component which is tied to an organization. This suggests that the positive relationship between negative emotions and turnover intentions as a means of coping with undesirable feelings will be weakened as organizational identification increases. However, the effect of identification may act more fundamentally to the emotion experience than a simple 
buffering effect, and aspects of secondary appraisal (i.e., blame/credit, coping potential, future expectations) speak to this effect.

The blame aspect of secondary appraisal for anger involves the intentional actions of another to block one's goals (Frijda, 1986; Lazarus, 1991a; Ortony, Clore, \& Collins, 1988). Self-definitions influence who or what is defined as 'other'. For an individual highly identified with the organization, anger directed toward the organization is similar to self-blame because the organization is part of one's self-definition. Self-blame is inconsistent with the feeling of anger (Roseman et al., 1996). Self-blame is also inconsistent with self-enhancement motives because it suggests the organization has done something wrong, thus lowering the regard for the organization. As a result, high organizational identification should bias individuals away from attributing responsibility for anger to the organizational in-group, and divert attention toward an ostensibly blameworthy out-group target (e.g., customers, competitors). As an example, last minute scheduling changes may anger an employee because they prevent that person from going to a personal gathering. The target of blame can vary even given the same anger-invoking event. If organizational identification is low, blaming the organization for irresponsible scheduling is a natural response. However, if organizational identification is high, blame could be turned toward clients who did not communicate needs properly or toward coworkers who called in sick.

Anger is also associated with coping potential appraisals that action will be beneficial and future expectancy appraisals that are favorable (Lazarus, 1991a). For those highly identified with the organization, anger should be engaging (as opposed to distancing) with the firm because the organization is viewed with a positive bias, likely to provide coping support and favorable future experiences. To continue with the aforementioned example, the organizational scheduling event, the individual may think, "the firm will correct the customer problems that led to this problem." 
Providing further evidence that anger engages the individual, given high identification, research has shown that conflict directed against one's group encourages group solidarity and commitment (Tajfel, 1982; Tajfel \& Turner, 1985). Poor treatment of the group by an external source strengthens the importance and value assigned to the group among those who identify with the group (Ashforth \& Kreiner, 1999; Branscombe, Schmitt, \& Harvey, 1999; Leach, Mosquera, Vliek, \& Hirt, 2010). In the context of work, the bias created by high organizational identification should divert blame from the organization and, in turn, engage the individual with his or her organization in the face of an anger-evoking event. Thus, we propose that when organizational identification is high, anger will decrease turnover intentions. We note that these effects are likely to be stronger for some events than others. In particular, when events leave room for interpretation, these effects would be most prominent, while the effects may be weaker for events that clearly involve organizational leaders or unmistakably implicate the organization's responsibility.

Hypothesis 1: Anger intensity is positively related to turnover intentions when organizational identification is low and negatively related to turnover intentions when organizational identification is high.

Similar to anger, guilt is a negative emotion. Per extant theory and research, it is expected to increase turnover intentions (Cropanzano et al., 1993; Maertz \& Griffeth, 2004) because leaving the organization frees individuals from the negative emotions created by work events. However, in light of secondary appraisals, guilt is quite different from other negative emotions in the work context (Ilies, Peng, Savani, \& Dimotakis, 2013). For guilt, blame appraisals are directed toward the self. Guilt is a self-conscious emotion (Tangney, 1999) resulting from individuals' awareness of their own shortcomings or wrong-doing (Lewis, 2008; Schmader \& Lickel, 2006). Guilt can be an emotion that "binds the person to the source of guilt and does not 
subside without reconciliation that tends to restore social harmony" (Izard, 1991: 355). Thus, despite being a negative emotion, guilt may bring an individual closer to the organization.

Whether the guilt response is a stronger bond with the organization or a greater distance from the organization depends on the nature of coping potential and future expectations secondary appraisals. Lazarus (1991a) described apologies (a form of engagement at work) as most likely to occur when guilty individuals believe the apology will rectify their mistakes (i.e., coping potential is high) and when this belief is accompanied by expectations that such mistakes can be avoided in the future (i.e., future expectations are positive). Individuals with high organizational identification, given their positive bias toward the organization and their motivation to stay in the organization's good graces, are expected to have secondary appraisals in favor of remaining in the organization. For example, an employee may feel guilty because of a mistake made with a client at work. If the employee is highly identified, a need to correct the mistake to ensure the organization is not perceived poorly is expected. Beliefs that the organization will support reconciliation attempts and will provide an environment conducive to preventing future mistakes will be high, facilitating reconciliation.

Guilt in a low- or non-identified individual is expected to increase considerations of organizational exit. In these cases, coping potential appraisals and future expectancy appraisals associated with remaining in the organization are not favorable. Thus, individuals may cope with guilt by avoiding those they feel guilty toward and/or reframing blame around another party (forms of disengagement) (Lazarus, 1991a). To remedy the feelings of guilt and prevent future occurrences, leaving the organization may be seen as a desirable option. Low organizational identification should precipitate these secondary appraisals because the organization can be reframed as the target of blame (e.g., the individual may think the organization could have 
prevented him or her from making the mistake).

Hypothesis 2: Guilt intensity is positively related to turnover intentions when organizational identification is low and negatively related to turnover intentions when organizational identification is high.

Pride is distinct in the primary appraisal process from both anger and guilt in that it is experienced due to goal congruence rather than goal incongruence. As such, pride is a positive emotion. Positive emotions have commonly been associated with increased employee retention (Cropanzano et al., 1993) because they create "psychological comfort," which motivates staying (Maertz \& Griffeth, 2004: 669). But, as with the other emotions, we theorize that the relationship between pride and turnover intentions will be influenced by organizational identification. Identification seems especially relevant given the core relational theme of pride to enhance “one's ego-identity by taking credit for a valued object or achievement, either our own or that of someone or group with whom we identify" (Lazarus, 1991a: 271).

Primary appraisals for pride include goal content involving enhancement of one's self- or social-esteem, and secondary appraisal regarding credit attributed to oneself. ${ }^{1}$ As such, pride's effects will depend on how the self is defined. Research suggests there is a crucial difference between those who interpret pride in relation to the self as a group member compared to those who experience pride as an individual (Helm, 2013). Pride can be engaging, binding a social group together (Helm, 2013; Tyler, 1999), but pride can also be disengaging, elevating the self above others (Kitayama et al., 2006, Smith, 2000).

When individuals are highly identified with the organization, we expect pride to be experienced as self-enhancing due to membership in a valued group. Remaining with this group,

\footnotetext{
${ }^{1}$ Secondary appraisals of coping potential and future expectations are not included in the Lazarus's (1991a) appraisal framework for pride; however, Lazarus (1991a) does suggest that a pride response includes an urge to publicly note successes.
} 
which has provided fertile conditions for success, should lead to self-enhancement through future success and pride experiences. Thus, the relationship between pride and turnover intentions is expected to be negative when organizational identification is high.

However, if organizational identification is low, pride may actually increase turnover intentions. When pride is attributed to oneself independently, it serves to reinforce one's value (Smith, Tong, \& Ellsworth, 2014) and increases self-confidence (Tracy \& Robins, 2007). Individuals to whom the organization is not central are expected to experience pride as elevating the self above the organization and to socially disengage as part of the pride response (Kitayama et al., 2006, Smith, 2000). As an example, if a teacher has a successful experience teaching a student, he or she may experience feelings of pride, but the response will depend on the teacher's identification with the organization. For the highly identified teacher, pride will be experienced in the context of the valued social group (e.g., the culture of this school facilitates student success) but without this identification, pride will be attributed to the self (e.g., I am incredibly talented!), facilitating inferences in favor of turnover (e.g., I am too good for this place). Thus, individuals unmoored from the organization are likely to experience pride as an emotion that distances them from the organization, increasing one's belief that leaving the non-valued group, given the individual's superiority, is a desirable option.

\section{Hypothesis 3: Pride intensity is positively related to turnover intentions when} organizational identification is low and negatively related to turnover intentions when organizational identification is high.

Despite the differences among anger, guilt, and pride, our theorizing leads to similar predictions for each. Emotion intensity increases turnover intentions among those with low organizational identification, but decreases turnover intentions among those with high organizational identification, notably independent of emotion valence. Yet, individuals can 
identify with more than one work-related group (Ramarajan, 2014) and make distinctions among different foci for identification (Ashforth et al., 2008). We have proposed that identifications matter because they psychologically contextualize the appraisal process and channel the coping responses. It would be overly simplistic to assume that only one identification is influencing these processes, given the multitude of social groups from which individuals may derive selfdefinition. However, theorizing and testing around many identities leads to very complex theory and, statistically, to four- or five-way interactions. Thus, we limited ourselves to occupational identification as an additional contextual factor.

\section{Occupational Identification}

Occupational identification captures the extent to which employees define themselves through membership in their current occupational group (i.e., in terms of the work that they do, Ashforth \& Kreiner, 1999; Gümüs, Hamarat, Çolak, \& Duran, 2012; Leavitt, Reynolds, Barnes, Schilpzand, \& Hannah, 2012). Occupational identification provides a valuable juxtaposition because it may complement or conflict with organizational identification. For example, Gouldner (1957) proposed organizational and occupational/professional bases as the primary work-focused identifications. ${ }^{2}$ Two types of employees were identified by Gouldner (1957) - locals (identified with the organization) and cosmopolitans (identified with the occupation). Subsequent research in this vein has emphasized either the conflict between these two bases of identification (e.g., when one identification is high and the other is low, Hekman, Bigley et al., 2009; Hekman, Steensma et al., 2009) or the benefits of high identification with both bases (e.g., work-identity complexity, Caza \& Wilson, 2009).

\footnotetext{
${ }^{2}$ We note that occupational and professional identification are similar constructs often used interchangeably though some distinctions exist. Professional identification is distinctive in the unique knowledge, skillsets, and prestige associated with the work one does (e.g., medicine; cf. Pratt, Rockmann, \& Kaufmann, 2006). However, both identifications are tied to the same theme of self-overlap with a group pursuing the same work.
} 
Anger, as noted earlier, will be appraised with blame directed outside of the organization when organizational identification is high, leading responses to involve engaging with the organization. This should be the case regardless of occupational identification since the focus is on other-blame and high organizational identification redirects blame. However, when organizational identification is low, occupational identification is expected to shape responses to anger. In this case, there is not a need to protect the organization from blame, so anger may leave individuals feeling that their goals are being blocked from within the organization. We propose that blame appraisals incorporating the organization will be especially salient when occupational identification is high because occupational goals may be at odds with organizational goals.

In support of this view, Hekman and colleagues theorized that when individuals were particularly identified with their work but not their organization, they would be especially sensitive to workplace events because the organization's management could be viewed as an enemy of good occupational activity (Hekman, Bigley et al., 2009; Hekman, Steensma et al., 2009). Employees with high levels of occupational identification and low levels of organizational identification are expected to use their occupational identification as a frame of reference, leading employees to frame behaviors of administrators (i.e., organizational representatives) negatively (Hekman, Steensma et al., 2009). This makes blame directed toward the organization especially likely when anger is experienced.

Furthermore, anger combined with high occupational and low organizational identification facilitates conclusions that coping potential and future expectations in the current work environment are low. Specifically, the current environment may be viewed as preventing the individual from fulfilling the role of a prototypical occupational member (i.e., an exemplary member, Hogg \& Terry, 2000) and from meeting occupational expectations. Because fulfilling 
the goals of occupation identification does not require the organization and the organization has demonstrated itself as a problematic context for motive fulfillment, exiting the organization may allow for more promising coping potential and future expectations to enact the occupational identity and fulfill identity motives. We expect that those low in occupational identification will still respond to anger with higher turnover intentions when organizational identification is low, because blame may turn toward the organization and leaving the organization may have more favorable coping potential and future expectations. However, we propose that the relationship will be strongest when occupational identification is high because of the "us (occupation) versus them (organization)" mentality that is created in this case.

Hypothesis 4: The relationship between anger intensity and turnover intentions is dependent on organizational and occupational identification, such that when organizational identification is high, anger intensity is negatively related to turnover intentions; when organizational identification is low, anger intensity is positively related to turnover intentions with the strength of this relationship increasing as occupational identification increases.

Guilt is distinct from anger with regard to secondary appraisals. When organizational identification is high, guilt should lead an employee to engage with the organization; in contrast, low organizational identification can lead the individual to cognitively separate the self from the guilt-creating environment, and even reframe the situation to push guilt toward the organization (Lazarus, 1991a). When both organizational and occupational identification are high, the negative relationship between guilt and turnover intentions should be especially strong because guilt will bind the individual to both the organization and the occupation. The occupational and organizational motives of self-consistency and self-enhancement encourage reconciliation. Remaining with the organization provides the greatest coping potential for rectifying the mistake, since the organization and the occupation are both valued groups. Future expectations should also be favorable because the organization and occupation are held in high regard and are 
expected to support the individual and create conditions to prevent future mistakes.

When individuals hold neither their occupation nor their organization in high regard, experiences of guilt may involve less need to make amends for failures within the organizational environment due to unfavorable appraisals of coping potential and future expectations. This is particularly true because the individual's failure involves the workplace, which is not central to the individual's identity needs. As a result, guilt is likely to be coped with either through separation and distancing from the work where the negative feelings of guilt were created (following a coping strategy known as 'situation selection,' cf. Elfenbein, 2007; Gross, 1998, 2008), or through reframing the guilt-inducing situation. Cognitive reframing is likely to redirect blame toward the occupation or the organization or both, increasing the desire to disengage. Thus, higher guilt intensity increases turnover intentions when both identifications are low. Predicting the response to guilt becomes most complicated when organizational identification is low and occupational identification is high. On the one hand, low organizational identification may lead to reframing blame secondary appraisals toward the organization. On the other hand, self-enhancement and self-consistency motives are likely to drive a need to make up for work failures that relate to one's occupation. Coping potential with members of the occupational group at work may be favorable. But future expectations, given the lack of identification with the organization, may be less favorable: while the current transgression may be dealt with through apology, there may be an expectation that guilt will reoccur because the organizational environment was partly responsible for the inducement of guilt. Taken together, this suggests that the engaging (with occupational members) and disengaging (from the organization) responses to guilt will be competing influences. Thus, we propose a weak negative relationship between guilt and turnover intentions when occupational identification is high and 
organizational identification is low.

To illustrate, if an employee commits an error in an interaction with a client, guilt should be especially engaging when both identifications are high (e.g., I must correct this mistake with the client and be a better occupational and organizational member in the future). Guilt should be especially disengaging when both identifications are low (e.g., the organization should have prevented this. I should leave, so I don't get into a similar situation in the future.). Finally, when occupational identification is high but organizational identification is low, the employee will feel conflicted (e.g., the organization is partially to blame, but I need to make up for this with my client), leading to a weak engagement response.

Hypothesis 5: The relationship between guilt intensity and turnover intentions is dependent on organizational and occupational identification, such that when organizational identification is high, guilt intensity is negatively related to turnover intentions with the strength of this relationship increasing as occupational identification increases; when organizational identification is low, guilt intensity is positively related to turnover intentions when occupational identification is low and weakly negatively related to turnover intentions when occupational identification is high.

Pride involves goal relevance, goal congruence, and enhancement of one's self- or social esteem. Experiences of pride at work indicate that the organizational context provides an environment where self-enhancement is possible. As such, we have proposed that a negative relationship exists between pride and turnover intentions when the individual is highly identified with the organization. When both organizational and occupational identification are high, the two identities reinforce the self-enhancing value of the current environment and the engaging nature of pride. Attributions of credit in the pride secondary appraisal are expected to be shared with the organization for providing a context for successful occupational enactment. Because social pride is engaging, we expect individuals with high levels of both identifications to be brought closer to others in the organization and occupation. Thus, the relationship between pride and turnover 
intentions is expected to be negative when organizational identification is high, with this relationship strengthened by increases in occupational identification.

When organizational identification is low, whether pride is engaging within the work context or disengaging will depend on occupational identification. Because pride involves giving credit rather than assigning blame, a lack of organizational identification when experiencing pride may make sharing credit with the organization less likely. However, secondary appraisals of credit for pride-invoking work experiences may extend to occupational members at work when occupational identification is high. Thus, when pride is experienced at work and occupational identification is high, the emotion engages employees with their colleagues. This suggests that staying with the organization is a function of increased attachment to colleagues more so than the organization. Thus, while there may be a negative relationship, it is not expected to be as strong as when organizational identification is high.

However, when both organizational and occupational identification are low, the pride goal content appraisals related to self or social esteem can be expected to lean toward selfesteem. Secondary appraisals of credit will be attributed to the individual's personal merits divorced from the current organization and occupation. Pride can elevate individuals above their organization and occupation (Kitayama et al., 2006; Smith, 2000). This seems especially likely because pride can be a "competitive emotion" (Lazarus, 1991a: 273), and is disengaging when self-focused (Kitayama et al., 2006). In turn, because neither the organization nor the occupation is central to future experiences of self-enhancement or self-consistency, the current environment may be seen as irrelevant or even as a hindrance rather than as a vehicle to future success.

To take an example, a teacher who is responding to pride experiences at work will be influenced by identification levels. A teacher highly identified with both the organization and the 
occupation is expected to experience pride with credit given to important social groups (e.g., my school features a positive student-teacher environment, my colleagues are supportive, and this has provided me the opportunity to succeed). If the teacher is not identified with the school but is highly identified with the occupation of teaching, the pride experience will engage the teacher with other members of the occupation (e.g., my colleagues are supportive and they have pushed me to provide a better learning experience for my students) but also link the teacher to the setting within which self-enhancement of the occupational identity is possible (i.e., the school).

However, if the teacher is unidentified with the occupation, pride secondary appraisals involve self-credit. In this case, the teacher may think about alternative options (e.g., I am so talented, I could make much more money in business).

Hypothesis 6: The relationship between pride intensity and turnover intentions is dependent on organizational and occupational identification, such that when organizational identification is high, pride intensity is negatively related to turnover intentions with the strength of this relationship increasing as occupational identification increases; when organizational identification is low, pride intensity is positively related to turnover intentions when occupational identification is low and is weakly negatively related to turnover intentions when occupational identification is high.

\section{METHODS}

\section{Participants and Procedure}

We tested our hypotheses in the training business unit of a large company in the transportation industry. The company employed 284 full time employees whose primary role was pilot training and certification. Employees were located at four different sites in the United States and Europe. Before beginning our data collection, members of the research team visited each site and met with employees to better understand the work conditions and to encourage participation in the study. Following these meetings, data collection occurred over a period of one year via online surveys, including an initial survey and multiple follow-up surveys. We 
employed experience sampling methodology to assess within-person variations in affective events across time. This approach allowed us to capture emotional reactions to affective events and intentions to turnover over the course of a year.

In the United States, employees were sent an initial survey and four follow up surveys at intervals of two months. In Europe, employees were sent an initial survey and two follow-up surveys. The initial survey included identification measures, a baseline measure of turnover intention, and control variables (i.e., age, tenure, marital status). For each of the follow-up surveys, we used an event contingent sampling strategy, whereby participants were asked to complete the survey based upon work events they reported experiencing in the past few days. Each follow up survey included questions concerning the discrete emotions that were elicited by work events and turnover intentions.

\section{Measures}

Discrete emotions. We measured feelings of anger, guilt, and pride, in response to workrelated events using a single emotion word (Shaver et al., 1987; Weiss et al., 1999). The work events were chosen based on management and employee feedback during our pre-data collection meetings. Specifically, two types of events appeared to be relevant in this particular organization. One set of work events was focused on general organizational issues, such as schedule and pay issues. The second set of events was focused on experiences of respect and meaning with regard to the job. It was relatively simple to ask about the general organization-related events, but it was less clear what to ask with regard to job issues. Thus, we developed a list of positive and negative events based on the work of Vignoles, Regalia, Manzi, Golledge, and Scabini (2006) regarding emotions and identity-related experiences. In the end, there were two sets of workrelated events: organizational (e.g., pay-related event, schedule-related event, organizational 
value) and job events (e.g., event that made you feel good at your job, event that made you feel disrespected). See Table 1 for a list of events that were included in the follow-up surveys.

Insert Table 1 here

In each follow-up survey, participants were asked, "To what extent did this event cause you to experience the following emotions?" with regard to each work-related event. Responses were on a five point scale ranging from 0 ("not at all") to 4 ("very strongly"). We then coded each emotion as the sum of the specific emotion reported across the events, such that each participant had a value for anger, guilt, and pride for that survey. As an example of this coding, those reporting multiple, high intensity anger experiences would have the highest values for anger, those who experienced no anger experiences would have the lowest values for anger, and those reporting only one high intensity anger experience or multiple moderate intensity anger experiences would have moderate values for anger. ${ }^{3}$

Turnover intentions. We measured turnover intentions in both the initial survey and all follow up surveys using the three-item scale from Cropanzano, Howes, Grandey, and Toth (1997). A sample item is "I would leave my job if a similar position were available at another company." Responses were on a five point scale ranging from 1 ("strongly disagree") to 5 ("strongly agree"). Coefficient alpha was .76 in the initial survey and .80 in the follow up surveys.

Organizational identification. Individual-level variables were assessed in the initial

\footnotetext{
${ }^{3}$ There are a number of ways we could have coded the data (i.e., the sum, the maximum, or the average of each emotion). Sum was the most theoretically appropriate since multiple high intensity affective events should have stronger overall effects than one high intensity affective event. To ensure the robustness of our results, we analyzed the data using each coding approach and findings were generally consistent. Specifically, the maximum produced very similar results but the three-way interaction for guilt was stronger while the interaction for pride was weaker. Using the average greatly decreased the variance of the emotion variables and hence, while the magnitude of the coefficients was similar, there were fewer significant conditional effects.
} 
survey. Organizational identification was measured with Mael and Ashforth's (1992) six-item scale. A sample item is "the company's successes are my successes," with higher scores indicating a stronger identification with the organization. The response scale was 1 ("strongly disagree") to 5 ("strongly agree"). Coefficient alpha was .87.

Occupational identification. Occupational identification was measured using three items from the social identity importance and centrality scale (Luhtanen \& Crocker, 1992) where the occupation of 'instructor' was inserted as the target of social identification. A sample item is "being an instructor is an important reflection of who I am," with higher scores indicating a stronger identification with the instructor occupation. The response scale was 1 ("strongly disagree") to 5 ("strongly agree"). Coefficient alpha was .83.

Control variables. We controlled for baseline turnover intentions as reported in the initial survey, so that our results would reflect those changes in turnover intentions that were due to affective work-related events rather than those due to some stable turnover tendency. We also controlled for three demographic variables - tenure, age, and marital status. Each of these variables are frequently included in turnover studies and have shown modest predictive strength (Griffeth, Hom, \& Gaertner, 2000). Age was also of potential interest because emotional experiences can vary across the lifespan (Carstensen, Pasupathi, Mayr, \& Nesselroade, 2000). In addition, tenure has long been considered to be related to organiational identification (Dutton et al., 1994). Tenure was reported in years and months of continuous employment with the company. Age was reported in increments of five, starting at 30, as all participants were over 30 years old. Marital status was coded as 0 for not currently married and 1 for currently married. Gender was not controlled because the sample was almost entirely male. We also repeated the analyses without the controls and found that this did not change the direction or significance of 
any of the results of interest reported here.

\section{RESULTS}

One hundred and sixty-eight pilot instructors (59\% response rate) completed the initial survey, and 135 of those instructors completed follow-up surveys. The final dataset consisted of 135 respondents, most of whom were male (95\%). The median reported age range was between 51 and 55 years old (ages ranged from 30 to 70 years). In total, the 135 pilot instructors completed 334 usable follow up surveys. Table 2 shows the means, standard deviations, and correlations for all study variables.

Insert Table 2 here

\section{Analytical Strategy}

The data contained a hierarchical structure in which episodic responses were nested within individuals. To account for these dependencies in the data, we used random coefficient modeling with HLM 6 (Bryk \& Raudenbush, 1996) to test our hypotheses. Because we took an episodic approach, we analyzed emotions and turnover intentions in the same follow-up survey, with identifications as the moderators and controlling for baseline turnover intentions. To separate within-person and between-person variance, we centered level 1 variables around each individual's mean and level 2 variables around the grand mean of the sample (Hofmann, Griffin, \& Gavin, 2000). Before testing our hypotheses, we ran a series of unconditional multilevel models to ensure there was sufficient within-person variance. Results indicated that $55 \%$ of the variance in anger, $63 \%$ in pride, and $57 \%$ in guilt was within-person. Finally, $58 \%$ of the variance in turnover intention was within-person.

\section{Hypothesis Testing}

We started our analyses with an examination of the main effects of discrete emotions 
(anger, pride, and guilt) on turnover intentions. Table 2 shows that both anger $(r=.30, \mathrm{p}<.01)$ and pride $(r=-.27, \mathrm{p}<.01)$ were correlated with turnover intentions. However, when multilevel considerations were taken into account, there was no longer a significant relationship between any of the discrete emotions and turnover intentions, as Model 1 of Table 3 shows.

Next, we investigated whether organizational identification moderated the within-person effects of anger, guilt, and pride on turnover intentions (see Table 3). Hypothesis 1 proposed that anger intensity is positively related to turnover intentions when organizational identification is low and negatively related to turnover intentions when organizational identification is high. Consistent with Hypothesis 1, as shown in Model 2 of Table 3, there was a significant cross-level interaction between anger and organizational identification $(b=-.07, p<.01)$. Figure 1 provides a graphical depiction of this moderated relationship. Simple slopes analyses showed that this relationship was negative when organizational identification was high (1 SD above mean, $t=-$ $3.16, p<.01)$ and positive when organizational identification was low ( 1 SD below, $t=2.43, p=$ .02). These findings support Hypothesis 1.

Hypothesis 2 proposed that guilt intensity is positively related to turnover intentions when organizational identification is low and negatively related to turnover intentions when organizational identification is high. Model 2 of Table 3 shows that the cross-level interaction of guilt and organizational identification on turnover intentions approached significance $(b=-.07, p$ $<$.10). Simple slopes analyses using the tools for probing multilevel interactions suggested by Preacher, Curran, and Bauer (2006) showed that the relationship between guilt and turnover intentions was negative when organizational identification was high $(t=-2.18, p<.05)$, as hypothesized, but was not significantly different from zero when it was low. Therefore, Hypothesis 2 received marginal support. 
Hypothesis 3 proposed that pride intensity is positively related to turnover intentions when organizational identification is low and negatively related to turnover intentions when organizational identification is high. Model 2 of Table 3 shows that the cross-level interaction effect of pride and organizational identification on turnover intentions was significant $(b=-.04, p$ $<.01)$. As shown in Figure 2, the interaction was consistent with our predictions. Simple slopes showed that this relationship was negative when organizational identification was high $(t=-2.74$, $p<.01)$ and positive when organizational identification was low $(t=3.31, p<.01)$. Therefore, Hypothesis 3 was supported.

\section{Insert Table 3 here and Figures 1 and 2 here}

Next, we investigated the conditional effects on the relationships when occupational identification is considered in addition to organizational identification. We took three steps to complete this analysis because three-way interactions are especially difficult to detect in field studies (McClelland \& Judd, 1993). As an initial test, we tested the three-way interactions of all emotions simultaneously in Model 3, knowing that power issues can be expected when estimating all of the parameters based on a sample size that is constrained (Dawson \& Richter, 2006). Next, we tested each of the emotions individually in order to increase the power of the omnibus test (Models 4, 5, and 6). Finally, we performed simple slopes analyses on the threeway interactions for each emotion using the tools provided by Preacher et al. (2006) and Dawson and Richter (2006). Simple slopes tests and plots are based on the individual emotion regressions. This set of steps provided us with a thorough and consistent set of analyses.

Hypothesis 4 proposed that the relationship between anger intensity and turnover intentions depends on organizational and occupational identification. Specifically, we expected the positive relationship between anger and turnover intentions to be strongest when 
organizational identification was low and occupational identification high. The three-way interaction for anger in Model 3 was not significant. Model 4 shows that when anger was tested separately, the three-way interaction was still not significant. Simple slopes analysis found some conditional effects for occupational identification, however these effects did not alter the basic relationships of the two-way interaction between anger and organizational identification. Therefore, we found little evidence that the moderated relationship between anger and turnover intentions was also conditional on occupational identification.

Hypothesis 5 stated that the relationship between guilt intensity and turnover intentions depends on both organizational and occupational identification. Once again, as evident in Model 3 in Table 3, the three-way cross-level interaction effect of guilt and organizational and occupational identification on turnover intentions was not significant. However, Model 5 shows that the three-way interaction was significant $(b=.20, p<.01)$ when tested separately. Simple slopes analysis revealed conditional effects on the relationship between guilt and turnover intentions that are plotted in Figure 3. The relationship between guilt and turnover intentions was negative when organizational identification was high and occupational identification was low $(t$ $=-3.87, p<.01)$ and when organizational identification was low and occupational identification was high $(t=-2.40, p<.05)$. Simple slope comparisons indicated that the relationship was stronger when organizational identification was high and occupational identification was low $(t=$ $-5.06, p<.01)$. This suggests that the within-person relationship between guilt and turnover intentions was conditional on the relative levels of both organizational and occupational identification. As predicted, the relationship was negative when organizational identification was high and occupational identification was low and when organizational identification was low and occupational identification was high. When both identifications were low, we predicted that the 
relationship would be positive; the trend was positive, but it was not significant. There was not a relationship between guilt and turnover intentions when both organizational and occupational identification were high. This pattern of results provides moderate support for Hypothesis 5.

Insert Figure 3 here

Our last tests concerned Hypothesis 6, which stated that the relationship between pride intensity and turnover intentions is dependent on organizational and occupational identification. This omnibus test of the interaction was significant in both Model 3 (simultaneous, $b=.02, p<$ .01 ) and Model 6 (individual $b=.02, p<.01$ ). Once again, we performed simple slopes analyses to probe this interaction further. Figure 4 depicts the conditional relationships graphically. When both organizational and occupational identification were low, there was a positive relationship between pride and turnover intentions $(t=4.50, p<.01)$. When organizational identification was high and occupational identification was low, there was a negative relationship between pride and turnover intentions $(t=-2.50, p<.05)$. When organizational identification was low and occupational identification was high, there was no relationship between pride and turnover intentions $(t=-.50, n . s$.$) . When both were high, there was a negative relationship between pride$ and turnover intentions $(t=-3.50, p<.01)$. As predicted, the conditional relationship between pride and turnover intentions depended on the relative levels of both organizational and occupational identification. The results suggest that the effect of organizational identification alone was sufficient to make pride-evoking events beneficial for employee retention, while the buffering effect of occupational identification was at least sufficient to prevent it from being harmful. Overall, these results support Hypothesis 6. 


\section{Supplemental Analyses}

Event Types. The results reported above are based on all affective event responses with no distinctions among the events. However, as noted earlier, two types of events were included in our data collection - organizational and job-related events. It is possible that different findings could emerge across different types of events. Specifically, we might expect the three-way interactions to emerge more strongly for job-related events because they are particularly relevant to the individual's occupation. Thus, we ran a supplementary analysis based on the two different categories of events (see Table 1 for the categorization of events and Table 4 for the analyses). The findings of this analysis were generally consistent with our prior analysis. Still, there were some additional findings with regard to job-related events.

For job-related events, the three-way interaction for anger was significant (Hypothesis 4, $b=-.18, p<0.01$ ). We performed simple slopes analyses and plotted this interaction (see Figure 5). In line with our expectations, we found a negative relationship between anger and turnover intentions when both identifications were high $(t=-2.10, p<.05)$ and a positive relationship between anger and turnover intentions when organizational identification was low and occupational identification was high $(t=3.38, p<.01)$. When occupational identification was low, the slopes were reversed, but neither was significantly different from zero.

\section{Insert Table 4 and Figure 5 here}

In addition, the two way interaction for guilt and organizational identification (Hypothesis 2) was significant for job-related events. In contrast to all events, there was a positive relationship between guilt and turnover intentions $(t=2.61, p=.01)$ for job events when 
both identifications were low. The findings for pride were consistent with those for all events.

Turnover Intentions and Objective Turnover. Our focus in this paper is on turnover cognitions; thus, we studied and found support for the effects of discrete emotions and identifications on turnover intentions. Yet, it is important from an organizational perspective to confirm that these intentions are relevant to actual turnover outcomes. The organization in our study provided archival data of actual turnover approximately six months after the last follow-up survey that could be linked to our data on turnover intentions. Employees that exited the organization were coded as 1 and those that did not exit were coded as 0 . Correlational analysis demonstrated that turnover intentions from our last survey were significantly correlated with actual turnover $(r=0.27, p<.01)$. We also ran survival analyses using Cox regression with time varying covariates (Anderson \& Gill, 1982) and found support for the relationship between turnover intentions and actual turnover $(\beta=.59, p<.01)$. These findings underscore the relevance and importance of our dependent variable.

\section{DISCUSSION}

The intent of this research was to advance understanding of how discrete emotions unfold in organizational environments to influence organizationally relevant outcomes. We proposed that the pattern of identifications that individuals had with their organization and occupation were likely to be key factors in the secondary appraisal process, because identifications provide a context in which employees' feelings are processed. In an experience sampling study of anger, guilt, and pride emotions at work, we found that their respective influence on turnover intentions depended on the extent to which employees identified with their organization and occupation. These findings provide evidence that the effects of affective events at work have much to do with the psychological context in which the specific emotions are experienced. 


\section{Implications for Theory and Research}

The current study makes several theoretical contributions. Past empirical research has often relied on symmetrical assumptions to investigate affective events at work (Elfenbein, 2007; Grandey, Tam, \& Brauburger, 2002; Wegge, van Dick, Fisher, West, \& Dawson, 2006). This research concludes that generally positive emotions are desirable and negative emotions are undesirable for organizations (Elfenbein, 2007; Maertz \& Griffeth, 2004). However, there is growing evidence that discrete positive and negative emotions can have unique effects that run counter to this basic premise (e.g., Ilies et al., 2013). Our study addresses this issue by considering the appraisal characteristics of discrete emotions. In doing so, we show that discrete emotions can influence work-related cognitions in ways that suggest a dark side of positive emotion and a bright side of negative emotion. More generally, our theory and findings suggest that when identifications are considered, the effects of discrete emotions can differ among emotions with similar valence (e.g., anger and guilt), and be similar for emotions with different valence (e.g., guilt and pride). Our theory and results thus demonstrate that recognizing the factors which can influence discrete emotion appraisals offers a more fine-grained understanding of the workings and consequences of affective experiences in organizations.

We drew on emotion-appraisal processes (Lazarus, 1991a) and social identity theory (Ashforth, 2001; Ashforth \& Mael, 1989; Tajfel \& Turner, 1985) to show that it is not enough to characterize specific discrete emotions as beneficial or detrimental, particularly with respect to turnover cognitions. Rather, these emotions must be investigated with consideration of how emotion secondary appraisals are shaped. Our theoretical integration points to the importance of identifications to this process. For example, the findings for anger show that an employee with high organizational identification may respond to feelings of anger with low rather than high 
withdrawal cognitions. In addition, the positive emotion of pride generally is associated with lower turnover intentions. However, for employees lacking in work-related identifications, feelings of pride contributed to increased turnover intentions and in this case, a positive emotion was associated with a negative organizational outcome.

Overall, our research suggests that future explorations into other discrete emotions as well as other variables that influence secondary appraisals would be promising. For example, future endeavors could address other discrete emotions with distinct secondary appraisal characteristics, such as hope (which has unfavorable, but not hopeless future expectations) and sadness (which has no blameworthy party and low coping potential) (Lazarus, 1991a). Variables beyond identifications may also influence secondary appraisals. For example, leader-member exchange may be relevant to coping potential and future expectations or organizational culture may influence how blame/credit appraisals are formed.

Our treatment of identification as a moderator also has implications for identity researchers, particularly for studies that incorporate more than one identity. Self-consistency and self-enhancement motives are relevant when an identification is high, but the approach to fulfilling these motives depends on the focal social group with which an individual identifies, as well as the set of the identifications. This is particularly interesting in the case of the selfenhancement motive for pride. We found that the effect of organizational identification alone was sufficient to make pride-evoking events conducive to employee retention, and that occupational identification had a buffering effect on turnover intentions for those experiencing pride. The results suggest that there is somewhat of a substitution effect, with high levels of organizational identification or high levels of occupational identification being sufficient for the organization context to fulfill self-enhancement needs. So long as either organizational or 
occupational identification were high, pride did not increase turnover intentions.

The interactions across all three emotions with identification provide evidence that workrelated identifications are powerful factors in how people sense-make around their emotions. Identification has frequently been associated with cognition, affect, and behavior (e.g., Ashforth et al., 2008). We clarify and extend these relationships in an organizational context. In our model, identification constrains behavioral intentions of leaving the organization, and we propose this occurs due to a relationship between work-related identification and the cognitive framing of affective events. Furthermore, in our supplementary analysis, we confirm that these intentions do lead to actual turnover outcomes. In sum, work-related identifications provide the psychological context within which people give meaning to what they do and experience at work. And, discrete emotions and their consequences cannot be understood within organizational settings unless we take such contextual variables into account.

\section{Implications for Practice}

This study also presents interesting practical implications. The first of which is that company practices and policies informed by a positive/negative affect approach (rather than discrete emotions), which seek to engender positive emotions and minimize negative emotions, may not have the intended effects. Among those not highly identified with their organizations or their work, positive employee emotions may actually increase turnover intentions while negative emotions can sometimes reduce the risk of turnover. Organizations have limited control over emotions in the workplace (Basch \& Fisher, 2000; Weiss \& Cropanzano, 1996). Our findings suggest a promising alternative for inoculating employees against the potentially turnover inducing effect of emotions. Enhancing work-related identification may actually turn affective events into turnover-reducing experiences. In particular, organizational identification was 
generally beneficial for buffering the negative effects of work-related emotions. Our theory and our empirical results also suggest that while occupational identity is not as powerful as organizational identity in turnover, it does play a complementary role.

Rather than focusing on suppressing workplace emotions, organizations should employ practices that encourage greater organizational identification. Sensegiving is a key contributor to identification processes (Ashforth et al., 2008; Gioia \& Chittipeddi, 1991), and organizational communication is key to sensegiving (DiSanza \& Bullis, 1999; Pratt, 2000). Managers can communicate organizational information that enhances the prestige of the organization, thereby making identification with the organization a contributor to the employee's self-enhancement needs (Smidts, Pruyn, \& Van Riel, 2001). Organizations can also sensegive through policies. For example, compensation systems that encourage employees to see themselves as members of an in-group working against out-group organizations should encourage identification (Long, 1978; Worchel, Rothgerber, Day, Hart, \& Butemeyer, 1998). Overall, this study emphasizes the value of encouraging identifications, especially those tied to the organization.

\section{Limitations}

Our theory is based on the fulfillment of self-enhancement and self-consistency motives as primary explanatory mechanisms for the specific nature of appraisal cognitions and turnover intentions; however, we were unable to measure secondary appraisal components or motive fulfillment cognitions. Also, we chose two commonly noted individual motives for identity and identification; however, there are other motives. For example, Ashforth (2001) noted six identity motives - knowledge, expression, coherence, continuity, distinctiveness, and enhancement. Clearly, identity in general, and identification with social groups in particular, are important to fulfillment of several individual needs. More detailed work addressing the two primary motives 
we selected (i.e., measuring the motives within the context of emotions) and expanding to include other motives has great potential to inform our understanding of how identification colors employee interpretations of the work environment.

The results indicate that occupational identification may be a particularly important area for additional development in regard to how identification influences interpretation of emotion. Organizational identification acted as a predictable moderator in our analyses. Both pride and anger interacted with organizational identification to increase turnover intentions when identification was low, but to decrease turnover intentions when identification was high. Guilt also interacted somewhat predictably with organizational identification as the relationship was negative when organizational identification was high. However, when occupational identification was added to our analyses, some results did not line up with predictions. For example, in the case of guilt, when organizational and occupational identification were both high, the relationship between guilt and turnover intentions trended slightly up (though not significantly). Perhaps the emotion of guilt turned to shame (a more negative holistic self-focused emotion, Lewis, 2008) when employees felt a strong self-overlap with both the organization and the occupation, thus counteracting the need to repair with a need for withdrawal. Further work is necessary to specify the effects of occupational identification more precisely.

We briefly addressed the nature of work events, and the results of the supplementary analysis suggest that additional research is needed. When splitting out job-related events, responses to anger were not as predicted when occupational identification was low. Though the slope was not significant, when both identifications were low, anger appeared to reduce turnover intentions for job-related events. This raises questions about other identifications or contextual factors that may shape the relationship between an emotion and work-related cognitions. We 
have identified an important piece of the puzzle, but there is more to explore.

From a methodological perspective, the sample used here was relatively homogeneous, primarily involving middle-aged men. The employees of this organization tended to be at later stages in their career. Although our theory is not contingent upon gender or age, empirically we cannot be certain that the findings generalize to women or younger employees (the youngest participants were in their thirties). Furthermore, this study was conducted in one organization, meaning there could have been other specific contextual characteristics that influenced the relationships we found. In other settings, employees may have greater reasons to stay with an organization based on financial and personal needs and may respond differently to affective events. Although our findings provide evidence that discrete emotions are given meaning in relation to identification, the limitations of the sample emphasize the importance of additional research developing our understanding of these effects.

Finally, the use of one-item measures of emotions is a limitation, though it is consistent with prior research on individuals' emotional responses (Mauss, Levenson, McCarter, Wilhelm, $\&$ Gross, 2005). Anger, guilt, and pride are familiar and commonly felt emotions, which most people are able to identify within themselves (Barrett, Gross, Christensen, \& Benvenuto, 2001; Izard, 1991; Shaver et al., 1987). The likelihood that individuals were capable of identifying their felt emotions using one well-known emotion word suggests that the use of one item emotion measures does not undermine the findings. In addition, group-centered emotions minimize the potential for common source biases such as social desirability, response tendencies, and trait affectivity. Still, it would be worthwhile in the future to consider other discrete emotions that have their own unique characteristics and to use multi-item emotion measures. 


\section{Conclusion}

This paper contributes to our understanding of affective events as complex phenomena that depend not simply on the positive or negative nature of emotions but rather on the emotion appraisal processes. For organizations, emotions are sometimes viewed as a problem that must be regulated (Ashforth \& Kreiner, 2002). However, our findings suggest the "problem of emotions" at work is not necessarily a problem at all; by fostering identifications, emotions at work may actually help organizations retain employees. In short, we feel and interpret the world through our self-definitions. 


\section{REFERENCES}

Abrams, D., Ando, K., \& Hinkle, S. (1998). Psychological attachment to the group: crosscultural differences in organizational identification and subjective norms as predictors of workers' turnover intentions. Personality and Social Psychology Bulletin, 24(10), 1027 1039.

Andersen, P. K., \& Gill, D. R. (1982). Cox's regression model for counting processes: A large sample study. Annals of Statistics, 10(4), 1100-1120.

Ashforth, B. (2001). Role transitions in organizational life: An identity-based perspective. New York: Routledge.

Ashforth, B. E., Harrison, S. H., \& Corley, K. G. (2008). Identification in organizations: An examination of four fundamental questions. Journal of Management, 34(3), 325-374.

Ashforth, B. E., \& Kreiner, G. E. (1999). "How can you do it?": Dirty work and the challenge of constructing a positive identity. Academy of Management Review, 24(3), 413-434.

Ashforth, B. E., \& Kreiner, G. E. (2002). Normalizing emotion in organizations: Making the extraordinary seem ordinary. Human Resource Management Review, 12(2), 215-235.

Ashforth, B. E., \& Mael, F. (1989). Social identity theory and the organization. Academy of Management Review, 14(1), 20-39.

Barrett, L. F., Gross, J., Christensen, T. C., \& Benvenuto, M. (2001). Knowing what you're feeling and knowing what to do about it: Mapping the relation between emotion differentiation and emotion regulation. Cognition \& Emotion, 15(6), 713-724.

Barsade, S. G., Brief, A. P., \& Spataro, S. E. (2003). The affective revolution in organizational behavior: The emergence of a paradigm. In J. Greenberg (Ed.), Organizational Behavior: The State of the Science (pp. 3-52). Mahwah, NJ: Lawrence Erlbaum and Associates.

Basch, J., \& Fisher, C. D. (2000). Affective events - emotion matrix: A classification of work events and associated emotions. In N. M. Ashkanasy, C. E. J. Hartel \& W. J. Zerbe (Eds.), Emotions in the Workplace: Research, Theory and Practice (pp. 36-48). Westport, CT: Quorum Books.

Branscombe, N. R., Schmitt, M. T., \& Harvey, R. D. (1999). Perceiving pervasive discrimination among African Americans: Implications for group identification and well-being. Journal of Personality and Social Psychology, 77(1), 135.

Bryk, A. S., \& Raudenbush, S. W. (1996). HLM: Hierarchical linear and nonlinear modeling with the HLM/2L and HLM/3L programs. Chicago, IL: SSI, Inc.

Butt, A. N., \& Choi, J. N. (2006). The effects of cognitive appraisal and emotion on social motive and negotiation behavior: The critical role of agency of negotiator emotion. Human Performance, 19(4), 305-325.

Butts, M., Becker, W., \& Boswell, W. (2015). Hot buttons and time sinks: The effects of electronic communication during nonwork time on emotions and work-nonwork conflict. Academy of Management Journal, 58(3), 763-788.

Caza, B. B. \& Wilson, M. G. (2009). Me, myself, and I: The benefits of work-identity complexity. In L. M. Roberts \& J. E. Dutton (Eds.), Exploring Positive Identities and Organizations, (pp. 99-123). New York: Routledge.

Carstensen, L. L., Pasupathi, M., Mayr, U., \& Nesselroade, J. R. (2000). Emotional experience in everyday life across the adult life span. Journal of Personality and Social Psychology, 79(4), 644-655. 
Carver, C. S., \& Harmon-Jones, E. (2009). Anger is an approach-related affect: evidence and implications. Psychological Bulletin, 135(2), 183-204.

Conroy, S. A., \& O'Leary-Kelly, A. M. (2014). Letting go and moving on: Work-related identity loss and recovery. Academy of Management Review, 39(1), 67-87.

Cooper, D., \& Thatcher, S. M. (2010). Identification in organizations: The role of self-concept orientations and identification motives. Academy of Management Review, 35(4), 516538.

Cropanzano, R., Howes, J. C., Grandey, A. A., \& Toth, P. (1997). The relationship of organizational politics and support to work behaviors, attitudes, and stress. Journal of Organizational Behavior, 18(2), 159-180.

Cropanzano, R., James, K., \& Konovsky, M. A. (1993). Dispositional affectivity as a predictor of work attitudes and job performance. Journal of Organizational Behavior, 14(6), 595 606.

Dasborough, M. T. (2006). Cognitive asymmetry in employee emotional reactions to leadership behaviors. Leadership Quarterly, 17(2), 163-178.

Dawson, J. F., \& Richter, A. W. (2006). Probing three-way interactions in moderated multiple regression: Development and application of a slope difference test. Journal of Applied Psychology, 91(4), 917-926.

DiSanza, J. R., \& Bullis, C. (1999). “Everybody identifies with Smokey the Bear” Employee responses to newsletter identification inducements at the US Forest Service. Management Communication Quarterly, 12(3), 347-399.

Dutton, J. E., Dukerich, J. M., \& Harquail, C. V. (1994). Organizational images and member identification. Administrative Science Quarterly, 39(2), 239-263.

Elfenbein, H. A. (2007). Emotion in organizations: A review and theoretical integration. Academy of Management Annals, 1(1), 315-386.

Ellemers, N., Van Rijswijk, W., Roefs, M., \& Simons, C. (1997). Bias in intergroup perceptions: Balancing group identity with social reality. Personality and Social Psychology Bulletin, 23(2), 186-198.

Elsbach, K. D., \& Kramer, R. M. (1996). Members' responses to organizational identity threats: Encountering and countering the Business Week rankings. Administrative Science Quarterly, 41(3), 442-476.

Ellsworth, P. C., \& Smith, C. A. (1988). Shades of joy: Patterns of appraisal differentiating pleasant emotions. Cognition \& Emotion, 2(4), 301-331.

Ellsworth, P. C., \& Scherer, K. (2003). Appraisal processes in emotion. In R. J. Davidson, K. R. Scherer \& H. H. Goldsmith (Eds.), Handbook of Affective Sciences (pp. 572-595). New York: Oxford University Press.

Fredrickson, B. L. (1998). What good are positive emotions? Review of General Psychology, 2(3), 300-319.

Frijda, N. H. (1986). The Emotions. London: Cambridge University Press.

Frijda, N. H., Kuipers, P., \& ter Schure, E. (1989). Relations among emotion, appraisal, and emotional action readiness. Journal of Personality and Social Psychology, 57(2), 212228.

George, J.M. (1989). Mood and absence. Journal of Applied Psychology, 74(2), 317-324.

Gioia, D. A., \& Chittipeddi, K. (1991). Sensemaking and sensegiving in strategic change initiation. Strategic Management Journal, 12(6), 433-448. 
Gooty, J., Gavin, M., \& Ashkanasy, N. M. (2009). Emotions research in OB: The challenges that lie ahead. Journal of Organizational Behavior, 30(6), 833-838.

Gouldner, A. W. (1957). Cosmopolitans and locals: toward an analysis of latent social roles. Administrative Science Quarterly, 2(3), 281-306.

Grandey, A. A., Tam, A. P., \& Brauburger, A. L. (2002). Affective states and traits in the workplace: Diary and survey data from young workers. Motivation \& Emotion, 26(1), 31-55.

Griffeth, R. W., Hom, P. W., \& Gaertner, S. (2000). A meta-analysis of antecedents and correlates of employee turnover: Update, moderator tests, and research implications for the next millennium. Journal of Management, 26(3), 463-488.

Gross, J. J. (1998). The emerging field of emotion regulation: An integretive review. Review of General Psychology, 2, 271-299.

Gross, J. J. (2008). Emotion regulation. In M. Lewis, J. M. Haviland-Jones \& L. F. Barrett (Eds.), Handbook of emotions (Vol. 3, pp. 497-513). New York: Guilford.

Gümüs, M., Hamarat, B., Çolak, E., \& Duran, E. (2012). Organizational and occupational identification: Relations to teacher satisfaction and intention to early retirement. Career Development International, 17(4), 300-313.

Helm, S. (2013). A matter of reputation and pride: associations between perceived external reputation, pride in membership, job satisfaction and turnover intentions. British Journal of Management, 24(4), 542-556.

Hekman, D. R., Bigley, G. A., Steensma, H. K., \& Hereford, J. F. (2009). Combined effects of organizational and professional identification on the reciprocity dynamic for professional employees. Academy of Management Journal, 52(3), 506-526.

Hekman, D. R., Steensma, H. K., Bigley, G. A., \& Hereford, J. F. (2009). Effects of organizational and professional identification on the relationship between administrators' social influence and professional employees' adoption of new work behavior. Journal of Applied Psychology, 94(5), 1325.

Hofmann, D. A., Griffin, M. A., \& Gavin, M. B. (2000). The application of hierarchical linear modeling to organizational research. In K. J. Klein \& S. W. J. Kozlowski (Eds.), Multilevel theory, research, and methods in organizations (pp. 423-468). San Francisco: Jossey-Bass.

Hogg, M. A., \& Terry, D. J. (2000). Social Identity and Self-Categorization Processes in Organizational Contexts. Academy of Management Review, 25(1), 121-140.

Hogg, M. A., Terry, D. J., \& White, K. M. (1995). A tale of two theories: A critical comparison of identity theory with social identity theory. Social Psychology Quarterly, 58(4), 255269.

Ibarra, H., \& Barbulescu, R. (2010). Identity as narrative: Prevalence, effectiveness, and consequences of narrative identity work in macro work role transitions. Academy of Management Review, 35(1), 135-154.

Ilies, R., Peng, A. C., Savani, K., \& Dimotakis, N. (2013). Guilty and helpful: An emotion-based reparatory model of voluntary work behavior. Journal of Applied Psychology, 98(6), 1051-1059.

Izard, C. E. (1991). The psychology of emotions. New York: Springer.

Izard, C. E. (2009). Emotion theory and research: Highlights, unanswered questions, and emerging issues. Annual Review of Psychology, 60, 1-25. 
Kitayama, S., Mesquita, B., \& Karasawa, M. (2006). Cultural affordances and emotional experience: socially engaging and disengaging emotions in Japan and the United States. Journal of Personality and Social Psychology, 91(5), 890-903.

Lazarus, R. S. (1991a). Emotion and adaption. New York: Oxford University Press.

Lazarus, R. S. (1991b). Progress on a cognitive-motivational-relational theory of emotion. American Psychologist, 46(8), 819-834.

Lazarus, R. S., \& Cohen-Charash, Y. (2001). Discrete emotions in organizational life. In R. Payne \& C. L. Cooper (Eds.), Emotions at Work: Theory, Research and Applications for Management (pp. 45-81). West Sussex, England: Wiley.

Leach, C. W., Mosquera, P. M. R., Vliek, M. L., \& Hirt, E. (2010). Group devaluation and group identification. Journal of Social Issues, 66(3), 535-552.

Leavitt, K., Reynolds, S., Barnes, C., Schilpzand, P., \& Hannah, S. (2012). Different hats, different obligations: Plural occupational identities and situated moral judgments. Academy of Management Journal, 55(6), 1316-1333.

Lench, H. C., Flores, S. A., \& Bench, S. W. (2011). Discrete emotions predict changes in cognition, judgment, experience, behavior, and physiology: A meta-analysis of experimental emotion elicitations. Psychological Bulletin, 137(5), 834-855.

Lewis, M. (2008). Self-conscious emotions: Embarrassment, pride, shame, and guilt. In M. Lewis, J. M. Haviland-Jones \& L. F. Barrett (Eds.), Handbook of Emotions (pp. 742456). New York: Guilford Press.

Lindebaum, D., \& Jordan, P. J. (2012). Positive emotions, negative emotions, or utility of discrete emotions? Journal of Organizational Behavior, 33(7), 1027-1030.

Long, R. J. (1978). The effects of employee ownership on organizational identification, employee job attitudes, and organizational performance: A tentative framework and empirical findings. Human Relations, 31(1), 29-48.

Luhtanen, R., \& Crocker, J. (1992). A collective self-esteem scale: Self-evaluation of one's social identity. Personality and Social Psychology Bulletin, 18(3), 302-318.

Mael, F., \& Ashforth, B. E. (1992). Alumni and their alma mater: A partial test of the reformulated model of organizational identification. Journal of Organizational Behavior, 13(2), 103-123.

Maertz, C. P., \& Griffeth, R. W. (2004). Eight motivational forces and voluntary turnover: A theoretical synthesis with implications for research. Journal of Management, 30(5), 667683.

Mauss, I. B., Levenson, R. W., McCarter, L., Wilhelm, F. H., \& Gross, J. J. (2005). The tie that binds? Coherence among emotion experience, behavior, and physiology. Emotion, 5(2), 175-190.

McClelland, G. H., \& Judd, C. M. (1993). Statistical difficulties of detecting interactions and moderator effects. Psychological Bulletin, 114(2), 376-390.

Moors, A., Ellsworth, P. C., Scherer, K. R., \& Frijda, N. H. (2013). Appraisal theories of emotion: State of the art and future development. Emotion Review, 5(2), 119-124.

Ortony, A., Clore, G. L., \& Collins, A. (1988). The cognitive structure of emotions. Cambridge: Cambridge University Press.

Pekrun, R. (2006). The control-value theory of achievement emotions: Assumptions, corollaries, and implications for educational research and practice. Educational Psychology Review, $18(4), 315-341$. 
Pelled, L.H., \& Xin, K.R. (1999). Down and out: An investigation of the relationship between mood and employee withdrawal behavior. Journal of Management, 25(6), 875-895.

Perry, R. P., Stupnisky, R. H., Hall, N. C., Chipperfield, J. G., \& Weiner, B. (2010). Bad starts and better finishes: Attributional retraining and initial performance in competitive achievement settings. Journal of Social and Clinical Psychology, 29(6), 668-700.

Pratt, M. G. (2000). The good, the bad, and the ambivalent: Managing identification among Amway distributors. Administrative Science Quarterly, 45(3), 456-493.

Pratt, M. G., Rockmann, K. W., \& Kaufmann, J. B. (2006). Constructing professional identity: The role of work and identity learning cycles in the customization of identity among medical residents. Academy of Management Journal, 49(2), 235-262.

Preacher, K. J., Curran, P. J., \& Bauer, D. J. (2006). Computational tools for probing interactions in multiple linear regression, multilevel modeling, and latent curve analysis. Journal of Educational and Behavioral Statistics, 31(4), 437-448.

Ramarajan, L. (2014). Past, Present and Future Research on Multiple Identities: Towards an Intrapersonal Network Approach. Academy of Management Annals, 8(1), 589-659.

Roseman, I. J., Antoniou, A. A., \& Jose, P. E. (1996). Appraisal determinants of emotions: Constructing a more accurate and comprehensive theory. Cognition \& Emotion, 10(3), 241-277.

Roseman, I. J., \& Smith, C. A. (2001). Appraisal theory: Overview, assumptions, varieties, controversies. In K. R. Scherer, A. Schorr, \& T. Johnstone (Eds.), Appraisal processes in emotion: Theory, methods, research (pp. 3-19). New York: Oxford University Press.

Schmader, T., \& Lickel, B. (2006). The approach and avoidance function of guilt and shame emotions: Comparing reactions to self-caused and other-caused wrongdoing. Motivation and Emotion, 30(1), 42-55.

Scott, B. A., \& Judge, T. A. (2006). Insomnia, emotions, and job satisfaction: A multilevel study. Journal of Management, 32(5), 622-645.

Shamir, B. (1991). The charismatic relationship: Alternative explanations and predictions. The Leadership Quarterly, 2(2), 81-104.

Shaver, P., Schwartz, J., Kirson, D., \& O'Connor, C. (1987). Emotion knowledge: Further exploration of a prototype approach. Journal of Personality and Social Psychology, 52(6), 1061-1086.

Smidts, A., Pruyn, A. T. H., \& Van Riel, C. B. (2001). The impact of employee communication and perceived external prestige on organizational identification. Academy of Management Journal, 44(5), 1051-1062.

Smith, C. A., Tong, E. M., \& Ellsworth, P. C. (2014). The differentiation of positive emotional experience as viewed through the lens of appraisal theory. In M. M. Tugade, M. N. Shiota \& L. D. Kirby (Eds.), Handbook of positive emotions (pp. 11-27). New York: Guilford.

Smith, R. H. (2000). Assimilative and contrastive emotional reactions to upward and downward social comparisons. In J. Suls \& L. Wheeler (Eds.), Handbook of social comparison (pp. 173-200). New York: Springer.

Tai, K., Narayanan, J., \& McAllister, D. J. (2012). Envy as pain: Rethinking the nature of envy and its implications for employees and organizations. Academy of Management Review, 37(1), 107-129.

Tajfel, H. (1982). Social psychology of intergroup relations. Annual Review of Psychology, $33(1), 1-39$. 
Tajfel, H., \& Turner, J. C. (1985). The social identity theory of intergroup behavior. In S. Worchel \& W. G. Austin (Eds.), Psychology of intergroup relations (pp. 7-24). Chicago: Nelson-Hall.

Tangney, J. P. (1999). The self-conscious emotions: Shame, guilt, embarrassment and pride Handbook of Cognition and Emotion (pp. 541-568). New York: Wiley.

Tracy, J. L., \& Robins, R. W. (2007). The psychological structure of pride: A tale of two facets. Journal of Personality and Social Psychology, 92(3), 506-525.

Tyler, T. R. (1999). Why people cooperate with organizations: An identity-based perspective. Research in Organizational Behavior, 21, 201-246.

Van de Ven, N., Zeelenberg, M., \& Pieters, R. (2009). Leveling up and down: the experiences of benign and malicious envy. Emotion, 9(3), 419.

Vignoles, V. L., Regalia, C., Manzi, C., Golledge, J., \& Scabini, E. (2006). Beyond self-esteem: influence of multiple motives on identity construction. Journal of Personality and Social Psychology, 90(2), 308.

Wegge, J., van Dick, R., Fisher, G. K., West, M. A., \& Dawson, J. F. (2006). A test of basic assumptions of affective events theory (AET) in call centre work. British Journal of Management, 17(3), 237-254.

Weick, K. E., Sutcliffe, K. M., \& Obstfeld, D. (2005). Organizing and the process of sensemaking. Organization Science, 16(4), 409-421.

Weiss, H. M., \& Cropanzano, R. (1996). Affective events theory: A theoretical discussion of the structure, causes and consequences of affective experiences at work. In B. M. Staw \& L. L. Cummings (Eds.), Research in Organizational Behavior (Vol. 18, pp. 1-74). Greenwich: JAI Press.

Weiss, H. M., Suckow, K., \& Cropanzano, R. (1999). Effects of justice conditions on discrete emotions. Journal of Applied Psychology, 84(5), 786-794.

Worchel, S., Rothgerber, H., Day, E. A., Hart, D., \& Butemeyer, J. (1998). Social identity and individual productivity within groups. British Journal of Social Psychology, 37(4), 389413. 


\section{TABLE 1}

\section{Event Descriptions and Types}

\begin{tabular}{lc}
\hline \multicolumn{1}{c}{ Event Description } & Event Type \\
\hline Pay-related event & Organization \\
Schedule-related event & Organization \\
Event that made you feel devalued by your organization & Organization \\
Event that made you feel important as a pilot instructor & Job \\
Event that made you feel good at your job & Job \\
Event that made you feel close to other pilot instructors & Job \\
Event that made you feel that you were not effective at your job & Job \\
Event that reminded you of what it means to be a pilot & Job \\
Event that made you feel disrespected as a pilot & Job \\
\hline
\end{tabular}


TABLE 2

Means, Standard Deviations, and Correlations among Study Variables

\begin{tabular}{|c|c|c|c|c|c|c|c|c|c|c|c|c|}
\hline Variable & $M$ & $S D$ & 1 & 2 & 3 & 4 & 5 & 6 & 7 & 8 & 9 & 10 \\
\hline \multicolumn{13}{|l|}{ Level one (within-person) } \\
\hline 1. Anger & 2.86 & 3.52 & & & & & & & & & & \\
\hline 2. Guilt & .45 & 1.25 & $.21^{* *}$ & & & & & & & & & \\
\hline 3. Pride & 3.97 & 4.70 & -.12 & -.01 & & & & & & & & \\
\hline 4. TOI & 2.55 & .75 & $.30^{* *}$ & -.07 & $-.27^{* *}$ & $(.80)$ & & & & & & \\
\hline \multicolumn{13}{|l|}{ Level two (between-person) } \\
\hline 5. Age & 6.27 & 2.08 & $-.12^{*}$ & $-.17^{* *}$ & .11 & $-.13^{*}$ & & & & & & \\
\hline 6. Married & .78 & .42 & -.05 & -.06 & .08 & -.10 & $.20^{*}$ & & & & & \\
\hline 7. Tenure & 5.90 & 5.05 & .03 & -.01 & .00 & -.01 & $.39^{* *}$ & -.03 & & & & \\
\hline 8. Initial TOI & 2.27 & .97 & $-.13^{*}$ & -.08 & $-.13^{*}$ & $.48^{* *}$ & -.02 & -.09 & .03 & $(.76)$ & & \\
\hline 9. Organizational Identification & 3.69 & .81 & $-.21^{* *}$ & .03 & .08 & $-.34^{* *}$ & .03 & .06 & .01 & $-.48^{* *}$ & $(.87)$ & \\
\hline 10. Occupational Identification & 3.44 & 1.02 & .02 & .07 & $.27^{* *}$ & $-.22^{* *}$ & $.27^{* *}$ & .11 & .12 & $-.17^{*}$ & $.26^{* *}$ & $(.83)$ \\
\hline
\end{tabular}

$N_{\text {(Level 1) }}=334 . N_{\text {(Level 2) }}=135$. Coefficient alpha provided along the diagonal. Anger, Guilt, and Pride were coded as 0 to 4 and summed across events. TOI $=$ Turnover Intentions. Age was coded in 5 year windows beginning at 30 . Married was coded at 1 if married and 0 in not. Tenure was coded in years. Initial TOI $=$ Turnover Intentions in initial survey.

$* *=p<.01, *=p<.05$ 
TABLE 3

Results for Moderated Effects of Emotions on Turnover Intentions

\begin{tabular}{|c|c|c|c|c|c|c|}
\hline Variable & Model 1 & Model 2 & Model 3 & Model 4 & Model 5 & Model 6 \\
\hline Intercept $\left(b_{00}\right)$ & $2.50^{* *}$ & $2.52^{* *}$ & $2.51^{* *}$ & $2.52^{* * *}$ & $2.48^{* * *}$ & $2.50^{* *}$ \\
\hline \multicolumn{7}{|l|}{ Level 1} \\
\hline Anger $\left(b_{10}\right)$ & .01 & -.02 & -.01 & -.02 & & \\
\hline Guilt $\left(b_{20}\right)$ & -.06 & -.03 & -.03 & & $-.08^{\dagger}$ & \\
\hline Pride $\left(b_{30}\right)$ & $-.02^{\dagger}$ & .00 & -.01 & & & -.01 \\
\hline \multicolumn{7}{|l|}{ Level 2} \\
\hline Age $\left(b_{01}\right)$ & $-.04^{\dagger}$ & $-.04^{*}$ & $-.04^{*}$ & $-.04^{*}$ & -.03 & $-.04^{*}$ \\
\hline Married $\left(b_{02}\right)$ & .06 & .04 & .05 & .04 & .08 & .05 \\
\hline Tenure $\left(b_{03}\right)$ & .01 & .01 & .01 & .01 & .01 & .01 \\
\hline Initial TOI $\left(b_{04}\right)$ & $.28^{* *}$ & $.28^{* *}$ & $.28^{* *}$ & $.27^{* *}$ & $.29^{* *}$ & $.29^{* *}$ \\
\hline Org ID $\left(b_{05}\right)$ & $-.13^{*}$ & $-.12^{*}$ & $-.12^{*}$ & $-.12^{*}$ & $-.11^{\dagger}$ & $-.11^{\dagger}$ \\
\hline Occ ID $\left(b_{06}\right)$ & $-.10^{\dagger}$ & $-.09^{\dagger}$ & $-.09^{\dagger}$ & $-.09^{\dagger}$ & $-.10^{\dagger}$ & $-.09^{\dagger}$ \\
\hline Org Id X Occ Id $\left(b_{07}\right)$ & & & .01 & .01 & .01 & .01 \\
\hline \multicolumn{7}{|l|}{ Cross Level Interactions } \\
\hline Anger X Org ID $\left(b_{11}\right)$ & & $-.07^{* *}$ & $-.06^{* *}$ & $-.06^{* *}$ & & \\
\hline Anger X Occ ID $\left(b_{12}\right)$ & & .01 & .01 & .01 & & \\
\hline Anger X Org Id X Occ Id $\left(b_{23}\right)$ & & & -.01 & -.02 & & \\
\hline Guilt X Org ID $\left(b_{21}\right)$ & & $-.07^{\dagger}$ & $-.10^{\dagger}$ & & $-.12^{*}$ & \\
\hline Guilt X Occ ID $\left(b_{22}\right)$ & & .06 & .04 & & .03 & \\
\hline Guilt X Org Id X Occ Id $\left(b_{23}\right)$ & & & .06 & & $.20^{* *}$ & \\
\hline Pride X Org ID $\left(b_{31}\right)$ & & $-.04^{* *}$ & $-.05^{* *}$ & & & $-.05^{* *}$ \\
\hline Pride X Occ ID $\left(b_{32}\right)$ & & $-.03^{*}$ & $-.02^{* *}$ & & & $-.05^{* *}$ \\
\hline Pride X Org Id X Occ Id $\left(b_{33}\right)$ & & & $.02^{* *}$ & & & $.02^{* *}$ \\
\hline$\sigma^{2}$ & .30 & .27 & .27 & .29 & .32 & .30 \\
\hline
\end{tabular}

$N_{\text {Level 1 }}=334 . N_{\text {Level 2 }}=135$. Initial TOI $=$ Turnover Intentions in initial survey.

Org ID = Organizational Identification. Occ ID = Occupational Identification.

$* *=p<0.01, *=p<0.05,{ }^{\dagger}=p<0.10$ 
TABLE 4

Supplemental Results for Moderated Effects of Emotions on Turnover Intentions

\begin{tabular}{|c|c|c|c|c|}
\hline & \multicolumn{2}{|c|}{ Job Events } & \multicolumn{2}{|c|}{ Organization Events } \\
\hline Variable & Model 1 & Model 2 & Model 3 & Model 4 \\
\hline Intercept $\left(b_{00}\right)$ & $2.52^{* *}$ & $2.51^{* * *}$ & $2.50^{* *}$ & $2.50^{* *}$ \\
\hline \multicolumn{5}{|l|}{ Level 1} \\
\hline Anger $\left(b_{10}\right)$ & -.01 & .00 & -.03 & -.02 \\
\hline Guilt $\left(b_{20}\right)$ & $.26^{* *}$ & $.27^{* *}$ & -.09 & $-.11^{\dagger}$ \\
\hline Pride $\left(b_{30}\right)$ & .01 & .01 & $-.08^{*}$ & $-.08^{*}$ \\
\hline \multicolumn{5}{|l|}{ Level 2} \\
\hline Age $\left(b_{01}\right)$ & $-.04^{*}$ & $-.04^{*}$ & -.04 & $-.04^{\dagger}$ \\
\hline Married $\left(b_{02}\right)$ & .04 & .05 & .06 & .06 \\
\hline Tenure $\left(b_{03}\right)$ & .01 & .01 & .01 & .01 \\
\hline Initial TOI $\left(b_{04}\right)$ & $.28^{* *}$ & $.28^{* *}$ & $.29^{* *}$ & $.29^{* *}$ \\
\hline Org ID $\left(b_{05}\right)$ & $-.12^{*}$ & $-.11^{*}$ & $-.11^{*}$ & $-.11^{*}$ \\
\hline Occ ID $\left(b_{06}\right)$ & $-.09^{\dagger}$ & $-.09^{\dagger}$ & $-.09^{\dagger}$ & $-.09^{\dagger}$ \\
\hline Org Id X Occ Id $\left(b_{07}\right)$ & & .01 & & .01 \\
\hline \multicolumn{5}{|l|}{ Cross Level Interactions } \\
\hline Anger X Org ID $\left(b_{11}\right)$ & $-.11^{*}$ & .01 & $-.09^{* *}$ & $-.09^{* *}$ \\
\hline Anger X Occ ID $\left(b_{12}\right)$ & .05 & .03 & .01 & .00 \\
\hline Anger X Org Id X Occ Id $\left(b_{23}\right)$ & & $-.18^{* *}$ & & -.02 \\
\hline Guilt X Org ID $\left(b_{21}\right)$ & $-.30^{* *}$ & $-.43^{* *}$ & -.08 & -.15 \\
\hline Guilt X Occ ID $\left(b_{22}\right)$ & -.05 & .12 & .10 & .04 \\
\hline Guilt X Org Id X Occ Id $\left(b_{23}\right)$ & & .40 & & .19 \\
\hline Pride X Org ID $\left(b_{31}\right)$ & $-.04^{* *}$ & $-.05^{* *}$ & $-.11^{* *}$ & $-.15^{* *}$ \\
\hline Pride X Occ ID $\left(b_{32}\right)$ & $-.03^{* *}$ & $-.03^{* *}$ & -.04 & -.05 \\
\hline Pride X Org Id X Occ Id $\left(b_{33}\right)$ & & $.03^{* *}$ & & $.12^{* *}$ \\
\hline$\sigma^{2}$ & .27 & .27 & .27 & .27 \\
\hline Pseudo- $\mathrm{R}^{2}$ & .33 & .33 & .32 & .34 \\
\hline
\end{tabular}

$N_{\text {Level 1 }}=334 . N_{\text {Level } 2}=135$. Initial TOI $=$ Turnover Intentions in initial survey.

Org ID = Organizational Identification. Occ ID = Occupational Identification.

$* *=p<0.01, *=p<0.05,{ }^{\dagger}=p<0.10$ 


\section{FIGURE 1}

Moderating Effect for Organizational Identification on Anger

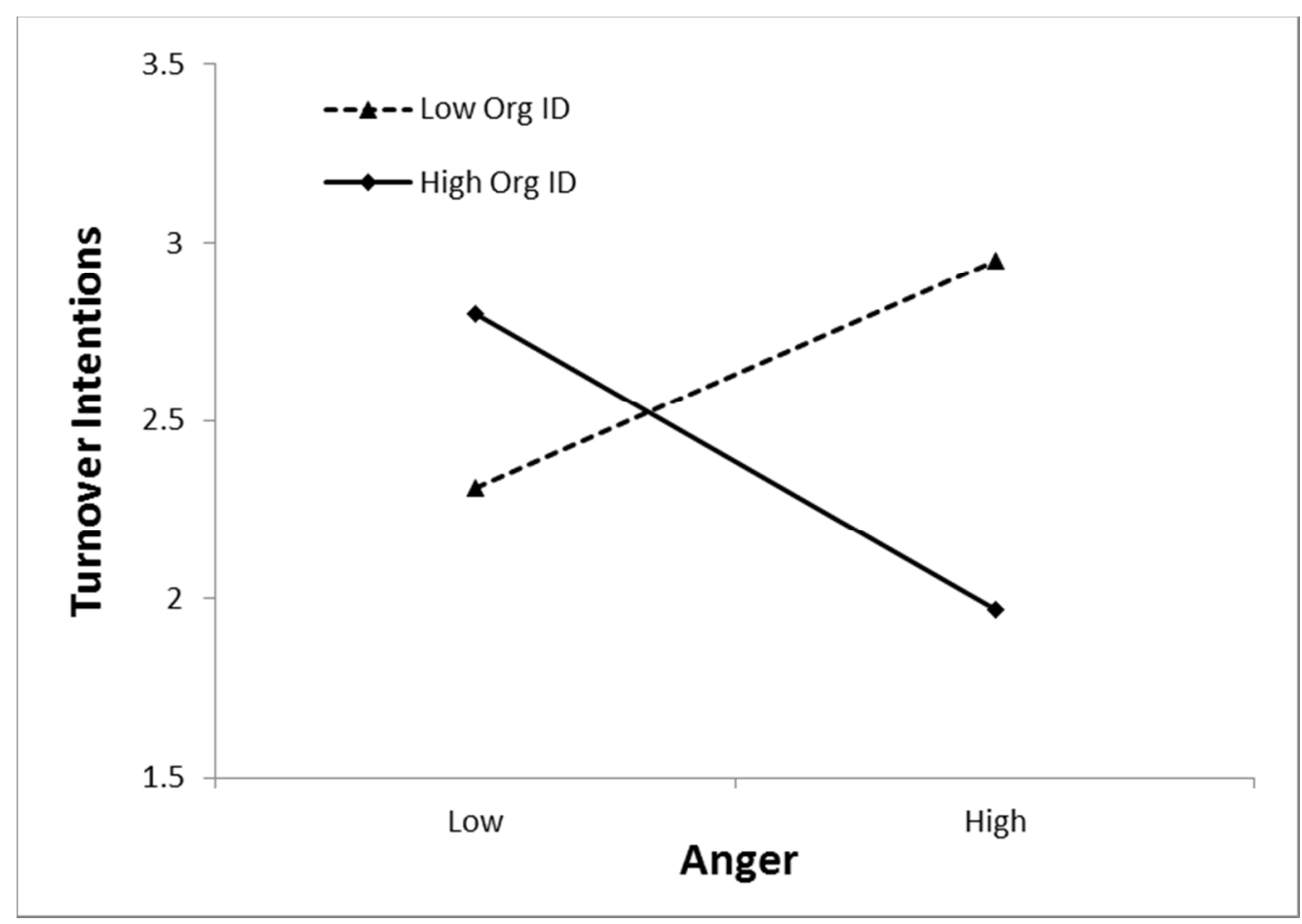

Note: Org ID = Organizational Identification. 


\section{FIGURE 2}

Moderating Effect for Organizational Identification on Pride

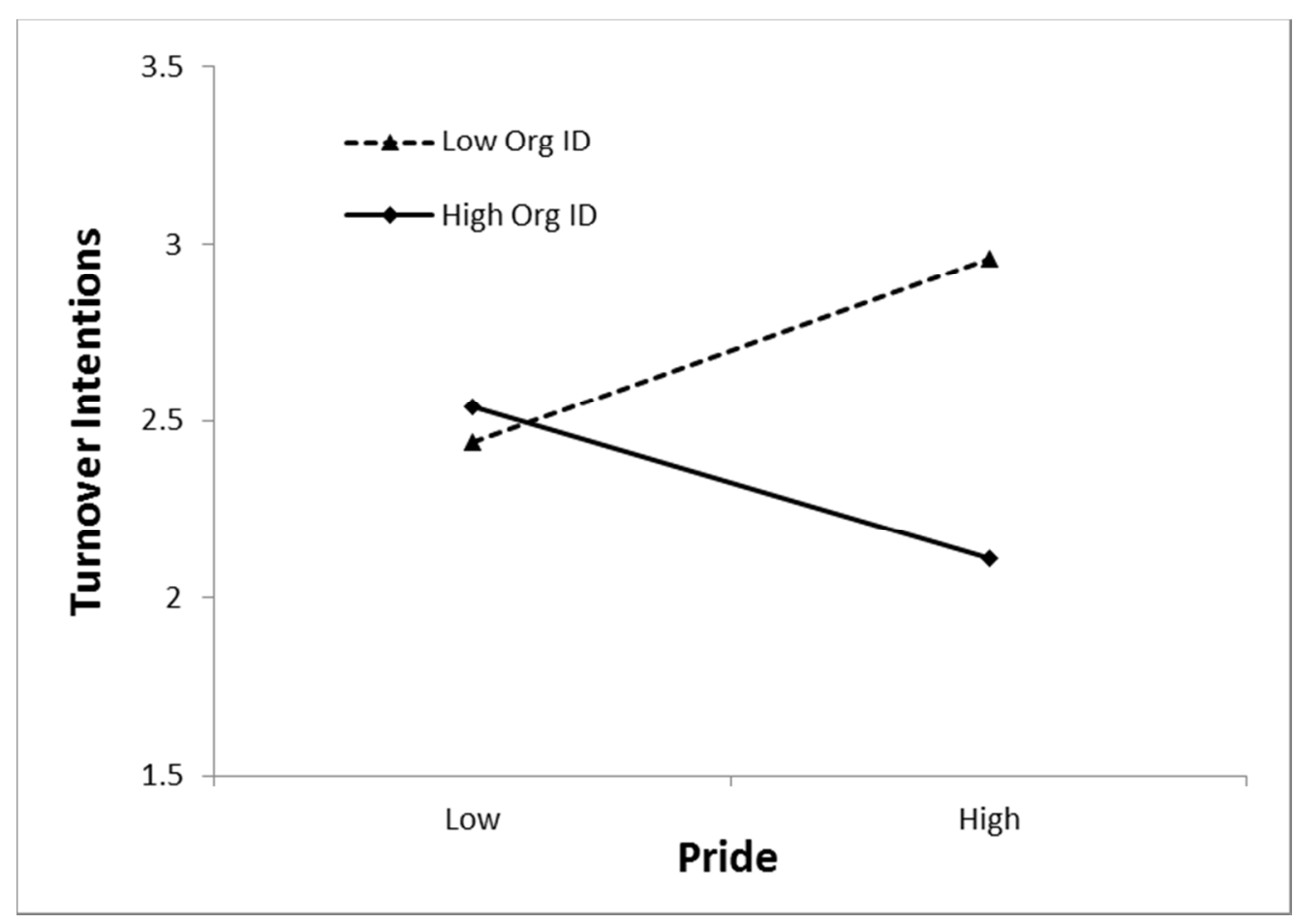

Note: Org ID = Organizational Identification. 
FIGURE 3

Moderating Effect of Organizational and Occupational Identification on Guilt

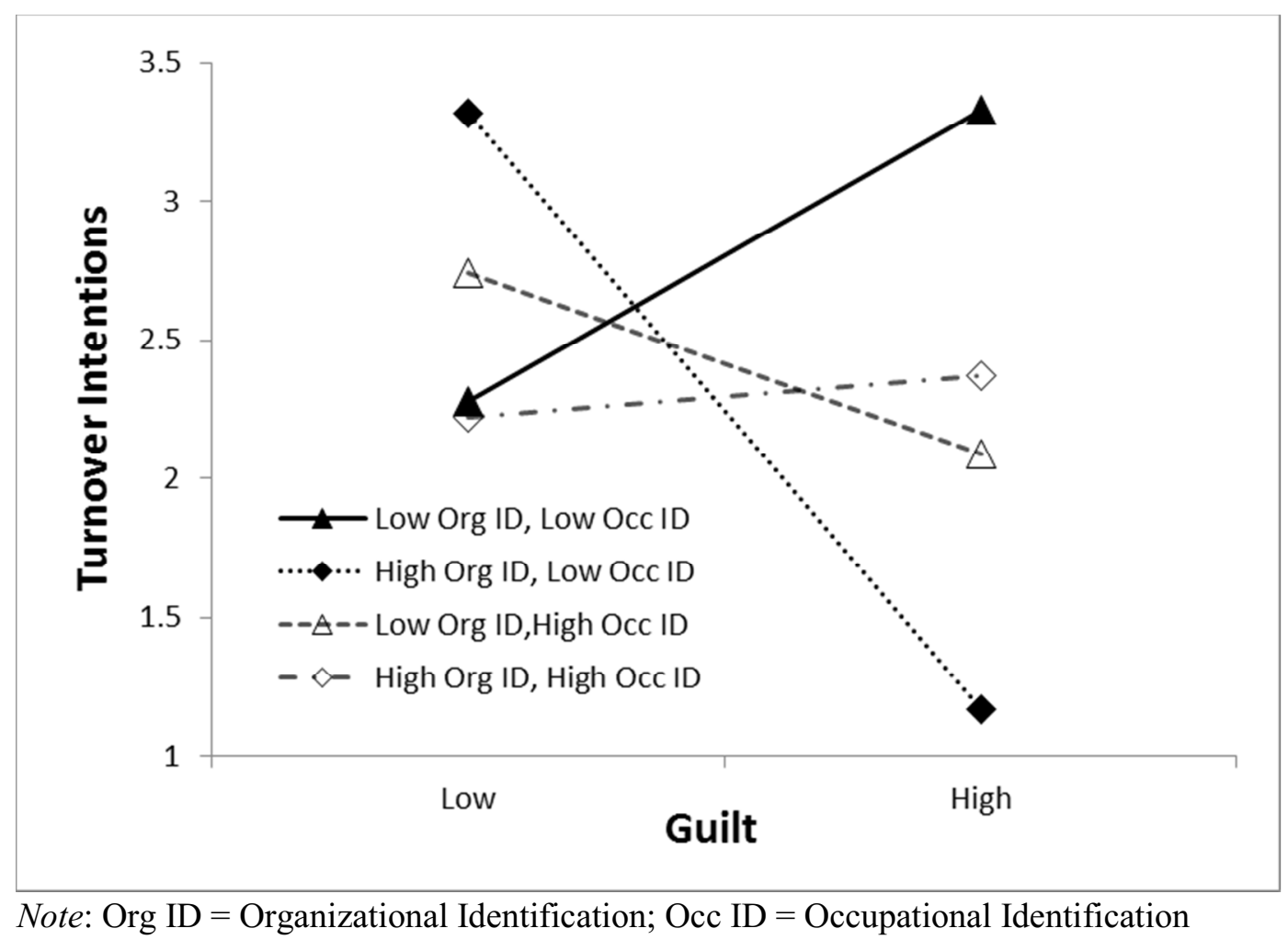

Note: Org ID = Organizational Identification; Occ ID = Occupational Identification 


\section{FIGURE 4}

\section{Moderating Effect of Organizational and Occupational Identification on Pride}

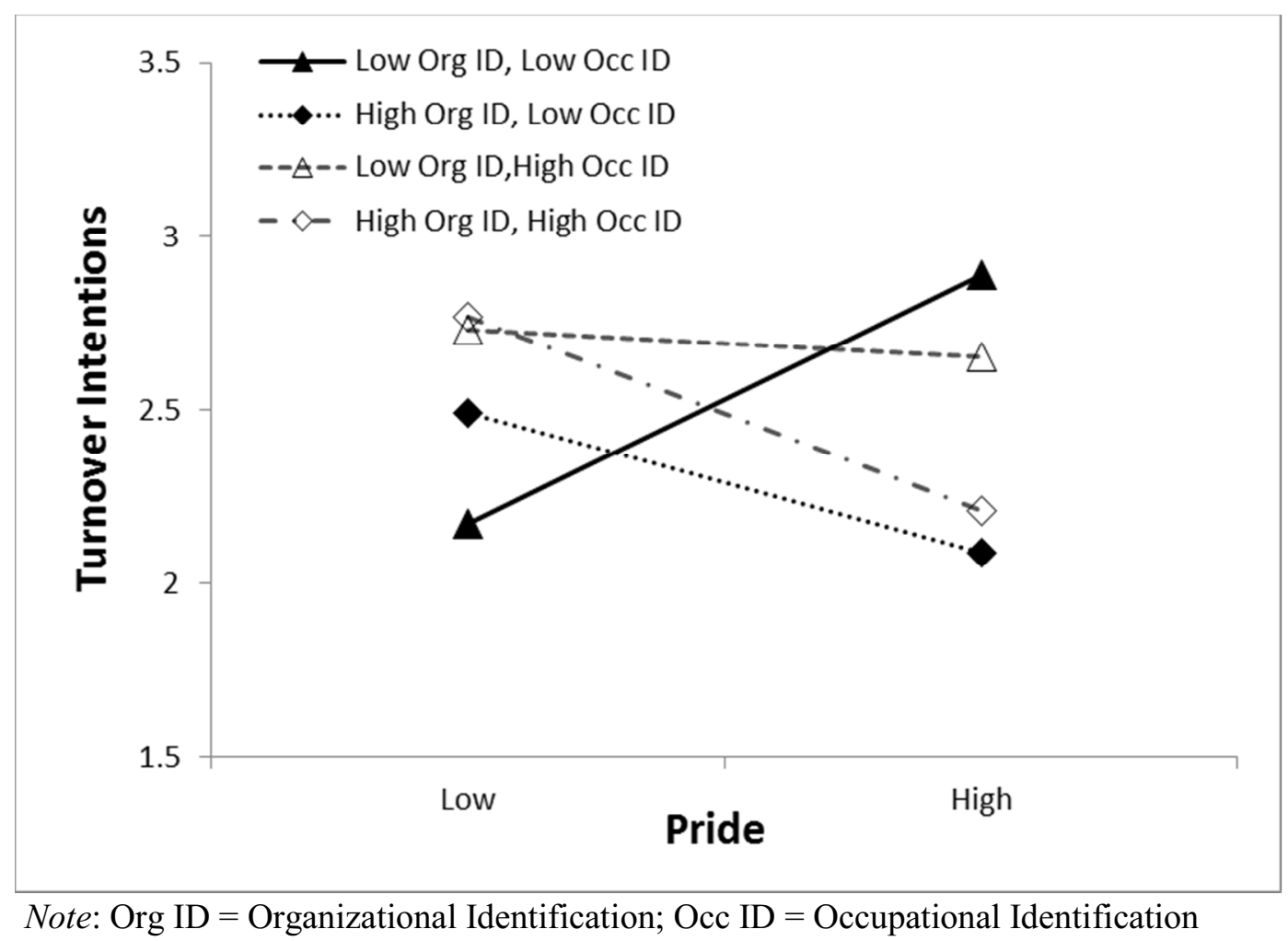

Note: Org ID = Organizational Identification; Occ ID = Occupational Identification 
FIGURE 5

Moderating Effect of Organizational and Occupational Identification on Anger (for Job Events)

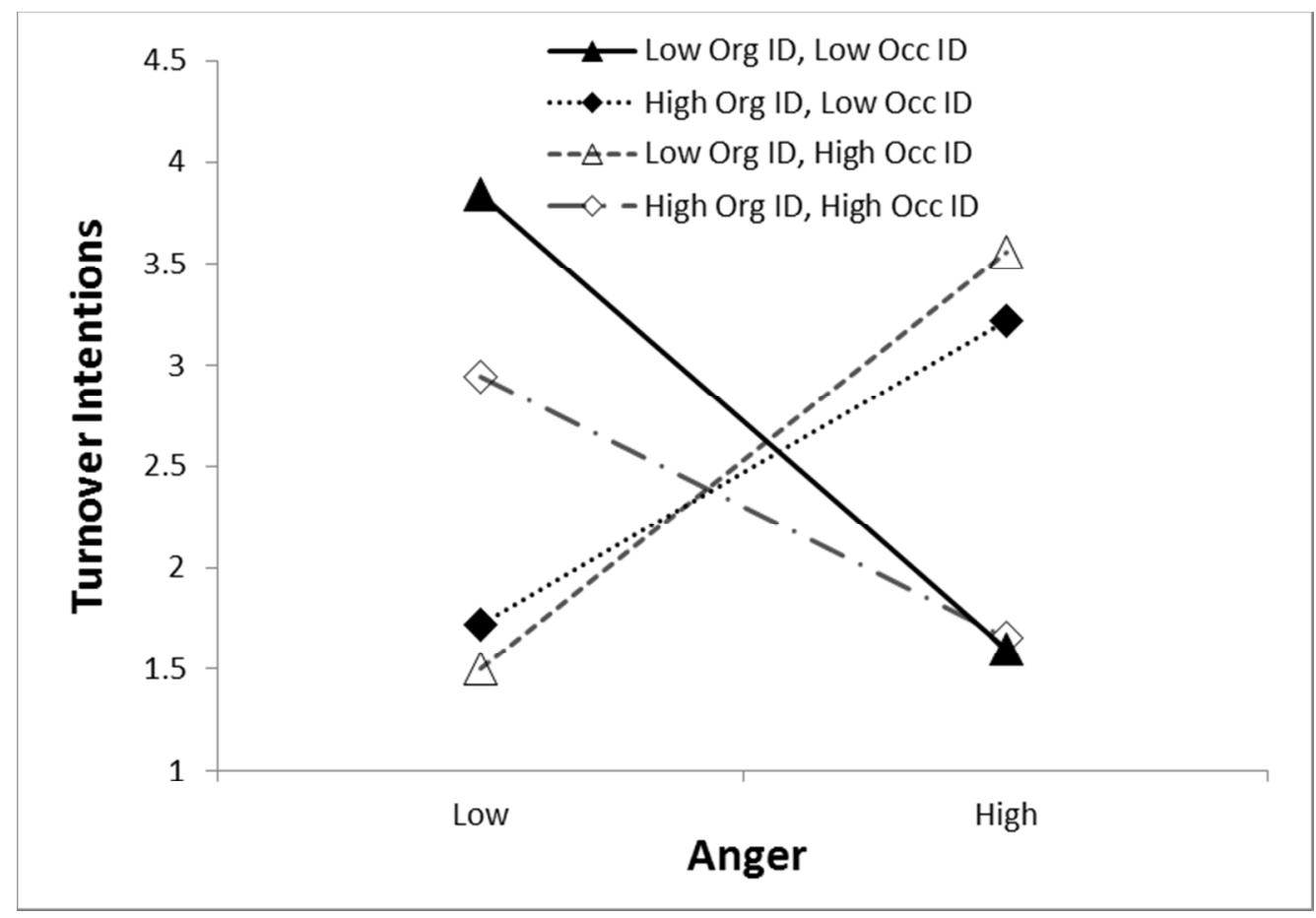

Note: Org ID = Organizational Identification. Occ ID = Occupational Identification 
Samantha A. Conroy (Samantha.conroy@colostate.edu) is an assistant professor of management in the College of Business at Colorado State University. She received her PhD from the University of Arkansas. Her research interests include work-related identity, emotions, and pay systems.

William J. Becker (beckerwj@yahoo.com) is an associate professor of management in the Pamplin College of Business at Virginia Tech. He received his PhD from the University of Arizona. His research interests include emotion, turnover, organizational neuroscience, and leadership.

Jochen I. Menges (jochen.menges@whu.edu) holds the Chair of Leadership and HRM at WHU - Otto Beisheim School of Management. He received his PhD in management from the University of St. Gallen, and is appointed as a University Lecturer at the University of Cambridge. His research focuses on leadership, emotions in organizations, and work motivation. 